Illinois State University

ISU ReD: Research and eData

Theses and Dissertations

10-17-2017

\title{
Teachers' Perceptions Of Addressing Leisure In Curriculum For Students With Severe Disabilities
}

Kara Klepp

Illinois State University, kara.klepp@gmail.com

Follow this and additional works at: https://ir.library.illinoisstate.edu/etd

Part of the Special Education Administration Commons, and the Special Education and Teaching Commons

\section{Recommended Citation}

Klepp, Kara, "Teachers' Perceptions Of Addressing Leisure In Curriculum For Students With Severe Disabilities" (2017). Theses and Dissertations. 807.

https://ir.library.illinoisstate.edu/etd/807

This Thesis is brought to you for free and open access by ISU ReD: Research and eData. It has been accepted for inclusion in Theses and Dissertations by an authorized administrator of ISU ReD: Research and eData. For more information, please contact ISUReD@ilstu.edu. 


\section{TEACHERS’ PERCEPTIONS OF ADDRESSING LEISURE IN CURRICULUM FOR}

\section{STUDENTS WITH SEVERE DISABILITIES}

\section{Kara Klepp}

\section{Pages}

This qualitative study was designed to examine the perspectives of addressing leisure in curriculum for students with severe disabilities. Quality of life discussions have shown the importance of considering skills to prepare them for adulthood which includes leisure outcomes. Research has examined many different aspects of transition including vocational education, but limited research has been conducted relating to leisure outcomes. Qualitative data obtained through semi-structured interviews indicated that more research is needed in leisure education including curriculum development and prioritization of skills taught. The participants reflected on their own definitions of leisure, current leisure outcomes, and the types of assessment and curriculum developed to promote leisure education. Overall findings suggest that teachers are using many of the best practices found in special education, but do not directly teach a structured leisure education program. Their current practices include teaching enhancement skills such as social skills, communication, choice making, and independent living goals, but do not teach specific core skills related to leisure development. Implications for future research include further examination on how we should assess leisure education core skills, the skills taught in a leisure curriculum, and how to evaluate leisure outcomes.

KEYWORDS: Transition, Leisure, Students, Severe Disability, Quality of Life 
STUDENTS WITH SEVERE DISABILITIES

KARA KLEPP

A Thesis Submitted in Partial Fulfillment of the Requirements for the Degree of

MASTER OF SCIENCE

Department of Special Education

ILLINOIS STATE UNIVERSITY 


\section{Copyright 2017 Kara Klepp}




\section{TEACHERS' PERCEPTIONS OF ADDRESSING LEISURE IN CURRICULUM FOR STUDENTS WITH SEVERE DISABILITIES}

KARA KLEPP

COMMITTEE MEMBERS:

Debra Shelden

Nicole Uphold

Karen Douglas 


\section{ACKNOWLEDGMENTS}

I would like to thank my committee members, family, and friends for the continuous support while researching a concept that is so important to me. I would like to thank Debbie Shelden for not only taking interest in my topic, but also for making me a better researcher. Her guidance, ideas, and assistance in developing this topic has improved my overall understanding of research. My committee members Nicole Uphold and Karen Douglas embraced my topic while guiding me to discover and interpret my findings. Their continuous encouragement inspired me to continue to seek out new challenges.

Additionally, I would like to thank my family and friends for their continued support both throughout this project and major life events. They took care of many everyday chores while my focus was drawn to research. Without their support, I would not have made it to the end of this project. I am very grateful for all the people who have contributed their time and energy to support me through this project.

K. K. 


\section{CONTENTS}

\section{Page}

ACKNOWLEDGMENTS

CONTENTS

ii

TABLES

$\mathrm{V}$

FIGURES

vi

CHAPTER I: INTRODUCTION AND STATEMENT OF PROBLEM

Quality of Life

Benefits of Leisure Education 3

Definitions of Leisure $\quad 4$

Leisure Development 5

Statement of Purpose and Research Questions $\quad 6$

CHAPTER II: REVIEW OF LITERATURE

$\begin{array}{ll}\text { Search Procedures } & 8\end{array}$

$\begin{array}{ll}\text { Overview of Quality of Life } & 8\end{array}$

Quality of Life and Leisure for People with Intellectual Disabilities 11

$\begin{array}{ll}\text { History of Leisure } & 18\end{array}$

History of Leisure for All 19

History of Leisure for People with Disabilities $\quad 21$

Leisure Education Development in Regular Education 22

Leisure Education Development in Special Education 26

$\begin{array}{ll}\text { Curriculum Development } & 31\end{array}$

Models of Curriculum Development for People with Intellectual Disabilities 32 
Individualized Education Plans

Current Practices

$\begin{array}{ll}\text { Recommendations for Improvement } & 41\end{array}$

CHAPTER III: METHODS 44

$\begin{array}{ll}\text { Methods } & 44\end{array}$

Procedures for Recruiting Teachers $\quad 44$

$\begin{array}{ll}\text { Participants } & 45\end{array}$

$\begin{array}{ll}\text { Interview Process } & 47\end{array}$

$\begin{array}{ll}\text { Security Procedures } & 48\end{array}$

$\begin{array}{ll}\text { Data Collection Procedures } & 48\end{array}$

$\begin{array}{ll}\text { Data Analysis } & 48\end{array}$

$\begin{array}{ll}\text { CHAPTER IV: ANALYSIS OF DATA } & 50\end{array}$

$\begin{array}{lr}\text { Analysis } & 50\end{array}$

$\begin{array}{lr}\text { Personal Definitions of Leisure } & 50\end{array}$

$\begin{array}{ll}\text { Leisure Outcomes } & 55\end{array}$

$\begin{array}{lr}\text { Assessment } & 59\end{array}$

$\begin{array}{ll}\text { Approach to Leisure Curriculum } & 63\end{array}$

Visual Representation of Leisure Education Development 73

$\begin{array}{ll}\text { CHAPTER V: DISCUSSION } & 79\end{array}$

$\begin{array}{ll}\text { Findings } & 79\end{array}$

$\begin{array}{ll}\text { Teacher Viewpoints } & 79\end{array}$

$\begin{array}{lr}\text { Family Support } & 80\end{array}$

$\begin{array}{ll}\text { Post-Secondary Placement } & 81\end{array}$ 
$\begin{array}{ll}\text { Leisure Curriculum } & 82\end{array}$

$\begin{array}{ll}\text { Barriers } & 83\end{array}$

$\begin{array}{ll}\text { Conclusions } & 84\end{array}$

$\begin{array}{ll}\text { Limitations } & 86\end{array}$

$\begin{array}{ll}\text { Implications for Future Research } & 87\end{array}$

$\begin{array}{ll}\text { Implications for Future Practice } & 88\end{array}$

$\begin{array}{lr}\text { REFERENCES } & 90\end{array}$

APPENDIX A: INTERVIEW QUESTIONS 97 


\section{TABLES}

Table

Page

1. Participant Information 


\section{FIGURES}

Figure $\quad$ Page

1. Flow Chart Based on Participant's Responses to Curriculum in Leisure Education 


\section{CHAPTER I: INTRODUCTION AND STATEMENT OF PROBLEM}

While education may serve many purposes, curriculum development should be focused on life fulfillment and happiness. The goal of education is to assist youth in developing necessary tools to have a successful life. Unfortunately, we often focus on success as it relates to career and financial status instead of allowing for an individualized definition of success based on one's values and priorities. Quality of life is dependent on much more than material wealth and sustainability. The definition of success may vary with each individual, influenced by life experiences, choice, and environment. Some define success as reaching goals in their professions, raising children, volunteering to help others, or finding a life interest or hobby.

Leisure participation of some sort in community environments should be considered part of success, as it leads to choices, social connections, and an overall well-being. It contributes to quality of life. Quality of life discussions are particularly important for people with intellectual disabilities, as the need to build skills, create community contacts, and plan for future supports starts early in their educational plans and continues through their transition from high school to adulthood.

\section{Quality of Life}

The construct of quality of life is critical to any discussion of curriculum development for students with intellectual disabilities. Schalock, Verdugo, Gomez, and Reinders (2016) “define quality of life as a multidimensional phenomenon composed of core domains that constitute personal well-being. These domains are influenced by personal characteristics and environmental factors." (p. 4-5). Curriculum considerations should also be linked to the eight core domains found in the core quality of life factors of personal well-being. These eight core domains include emotional well-being, interpersonal relations, material well-being, personal 
development, physical well-being, self-determination, social inclusion, and civil rights (Schalock, Verdugo, Jenaro, Wang, Wehmeyer, Jiancheng, \& Lachapelle, 2005). A student can expand and develop skills to improve quality of life when these areas are targeted in curriculum development.

Schalock et al. (2016) stated that quality of life for individuals with intellectual disabilities can be achieved through experience, education, environment, culture, and opportunity, as well as through individualized instruction, supports, accommodations and modifications, and access to opportunities. Many of these opportunities can be found in the form of leisure activities. Quality of life is enhanced by “developing personal talents, maximizing personal involvement, providing individualized supports, and facilitating personal growth opportunities" (Schalock et al., 2016, p. 4). The current structure and emphasis in education focus on student growth in academic and vocational training. Vocational education has taken priority over leisure education due to the value society currently places on material wealth (Datillo, 2008). This trend leaves gaps in leisure education. This has negative outcomes for adults with disabilities, who are often excluded from the workforce and hence have an abundance of free time with little activity or skills, knowledge, or awareness to fill the time (Datillo, 2012). Students with intellectual disabilities should have curriculum developed based on a prioritization of skills targeting a specific outcome.

Leisure education has been examined and found useful, yet many times it is ignored in both research and practice. Between the years of 1978 and 2016, the journal Career Development and Transition for Exceptional Individuals mentions leisure in 125 articles, but focuses on leisure education in only 5 articles. In contrast, vocation is mentioned in 575 articles and vocational education is mentioned in 567 articles. This wide imbalance of research and 
practice between vocational education and leisure education shows that the holistic nature of transition services reflected in federal legislation and articulated as a value in curriculum for students with significant disabilities is not being realized. How important is leisure education when determining quality of life, and to what extent is that importance reflected in practice?

\section{Benefits of Leisure Education}

Leisure is just one of 24 quality of life subdomains found in Schalock and Verdugo's (2016) framework, which makes it appear to be a small piece of a large puzzle. However, leisure can also be connected to other subdomains, including contentment, self-concept, stress management, interactions, relationships, performance, health, personal control, personal values, choice, community integration, and legal rights (as cited in Verdugo, Nevas, Gomez, \& Schalock, 2012). These connections suggest leisure may be very important to developing a high quality of life. Brajsa-Zganec, Merkas, and Sverko (2011) found leisure activities play a very important role in the quality of life of everyday citizens in Croatia, because they provide opportunities for people to meet their life values and needs. Through leisure activities, quality of life improved as social relationships, positive emotions, and skill acquisition developed. Brajsa et al. (2011) concluded that there is a positive relationship between participation in leisure and social well-being.

Similar concepts were found important by The United Nations Convention on the Rights of Persons with Disabilities (2006). Quality of life for all includes participation in cultural life, recreation, leisure and sport as an objective "to promote, protect and ensure the full and equal enjoyment of all human rights and fundamental freedoms by all persons with disabilities, and to promote respect for their inherent dignity" (as cited in Verdugo et al., 2012, p. 1038). These 
reforms are to ensure that people with disabilities have the same human rights and quality of life as people without disabilities.

\section{Definitions of Leisure}

Defining leisure has proven difficult as experiences, values, and considerations create different, unclear, and sometimes vague definitions. Aitchison (2009) found that the field of leisure studies has omitted consideration of people with disabilities. Another problematic aspect of leisure definitions is the tendency to equate leisure to time away from work. This definition ignores many people who are disproportionally out of the workforce, including women, elderly people, and individuals with intellectual disabilities (Hutchison \& McGill, 1992). As people with disabilities are unemployed at higher rates than people without disabilities, this population is not considered when discussing leisure as time away from work. As work leads to financial stability, leisure has also been looked from a consumption perspective, as costs are often associated with sports, tourism, etc.

Deinstitutionalization has also changed the definition of leisure for people with intellectual disabilities. Leisure activities have been considered and used as an approach to different types of therapy. These therapeutic programs become part of a regimented schedule with goals and objectives changing the function of leisure as the purpose of the activity. Therapies through music, horticulture, animal care, swimming, and other activities took on a medical based function taking out leisure components such as choice, preference, and selfinitiation (Hogg \& Cavet, 1995). This ideology leads to an environmental dependency on staff and structure and less likely makes spontaneous leisure experiences based on interests, friendships, and choices (Hutchison \& McGill, 1992). The comparison between leisure counseling as a therapeutic form and leisure participation as a recreation form continues to 
challenge a clear understanding of the enjoyment of leisure activities when completed as a necessity of therapy for medical purposes.

“The AAIDD defines leisure as available free choice time and the individually selected activities that characteristically are not related to work or to other obligatory forms of activity and which are expected to promote feelings of pleasure, friendship, happiness, spontaneity, fantasy or imagination, fulfilment, creativity, self-expression and self-development" (as cited in Badia, Orgaz, Verdugo, Ullan, \& Martinez, 2013, p. 534). Aitchison (2009) found that leisure revolves more around the people who "they encounter, engage with, and interact with as a result of their leisure." (p. 377). The dependence on others prohibits the freedom of choice of leisure activities and ability to create social networks independently.

\section{Leisure Development}

Even with strides in leisure education in the 1990s, progress in curriculum development and implementation in schools is lacking. Specific details on how to teach, when to teach, and why to teach leisure education are still being debated. However, researchers suggest following a holistic approach to education results in the most meaningful outcomes. Verdugo et al. (2012) found that person-centered planning and individualized supports allowed for people with disabilities to make their own decisions based on their own interests. Claes, Van Hove, Vandevelde, van Loon, and Schalock (2012) also recommended person-centered planning as a holistic approach to education especially when considering ecological inventories and the frequency of accessed environments. Modell and Valdez (2002) described best practice as exposure to the different types of activities and the skills necessary to participate in the activity. Vandercook (1991) suggested skill fluency, maintenance, and generalization with the use of natural cues continue to be a priority when educating students with severe disabilities. Snell 
(2009) discussed the importance of purposeful instruction for students with disabilities, including strategies such as chaining, shaping, prompting, time-delay, and error correction which are the best practices in systematic and direct instruction. Even with all the research, strategies, and resources, a lack of leisure education for individuals with disabilities continues to be a norm in public education (Snell, 2009).

The strategies listed above are best practices in teaching a wide variety of skills to students with severe disabilities. Modell and Valdez (2002) found that skill development in leisure education should be considered, as many students with severe disabilities value leisure time activities. They like to go out for dinner, see a movie, participate in community events, and be involved in activities. Exposure to activities are also important; people develop a repertoire of activities that are preferred through exposure and experience (Modell \& Valdez, 2002). Leisure skills can be developed through school and community extra-curricular activities. However, teachers struggle to understand activity preference, plan leisure activities, and teach skills needed for planning and initiating leisure activities (Snell, 2009). Without developing these skills and self-initiation, people with disabilities might lack the knowledge in completing these after high school.

\section{Statement of Purpose and Research Questions}

A teacher's goal should be to prepare students to obtain a high level of quality of life. Many times, the focus on outcomes is primarily related to employment as a source of both income and purpose (Mithaug, Horiuchi, \& Fanning, 1985). However, many students with intellectual disabilities have an extended amount of free time that is not used purposefully (Patterson \& Pegg, 2009; Datillo, 2013). By overlooking recreation and leisure, we potentially set up students for a decreased quality of life. 
Limited research on current perceptions, implementation, and outcomes of leisure education is available. No research currently exists on the development and implementation of leisure programming for students with severe disabilities in public education systems. Research on developing transitions goals for the IEP is also lacking. The purpose for this study is to see how teachers are incorporating leisure outcomes and curriculum into transition planning for students with intellectual disabilities. Through this study, I would like to examine how teachers include recreation and leisure in their curriculum. My specific research questions are

1. What value do teachers place on leisure?

2. What are the perceptions of $<$ teachers $>$ regarding recreation and leisure outcomes and programming for individuals with severe disabilities? 


\section{CHAPTER II: REVIEW OF LITERATURE}

Through this study, I examined the perceptions of teachers of on addressing leisure in curriculum and transition planning for students with intellectual disabilities. This chapter provides an overview of literature related to leisure education. First, I review the literature related to quality of life for people with disabilities including a) overview of quality of life, b) environmental factors, c) choice, and d) social connections. Second, I present a brief history of leisure, including a) society development of leisure b) including people with disabilities c) leisure education d) leisure education versus physical education, e) models of leisure education, and f) leisure education adapted for people with intellection disabilities. Next, I review values about curriculum, covering a) individualized education plans, b) teachers, c) current practices, and d) recommendations for improving leisure education.

\section{Search Procedures}

My search terms included quality of life and leisure education in curriculum development. I began with searches on ERIC, PsychINFO, and SAGE publications. I searched for peer reviewed articles using the key search terms of leisure education, quality of life, disabilities, secondary education, and transition planning. I also examined reference pages of current research articles to locate articles, books, and resources that included leisure education.

\section{Overview of Quality of Life}

Over the last 40 years, recognized rights of persons with disabilities have changed significantly (Verdugo et al., 2012). However, quality of life and leisure participation still has room for development and improvement. Verdugo et al. (2012) found that social rights need further development; people with disabilities still lack equal opportunities. The quality of life concept is important to people with intellectual disabilities and must be considered when 
planning, delivering, and evaluating individualized services and supports (Schalock et al., 2005).

The concept of quality of life demands we include citizens with intellectual disabilities in experiencing the same human rights and quality of life as any other member of society. The concept and action to achieve quality of life for all is the beginning process in achieving equal opportunities for people with disabilities. Quality of life is heightened when a person's needs are met and when the individual can pursue life enrichment in major life settings (Verdugo et al., 2012). This concept covers the basis of leisure participation for all people.

Schalock et al. (2016) described eight core domains of quality of life in the literature, and those domains have been defined with respective indicators. These eight essential domains include: emotional well-being, interpersonal relationships, material well-being, personal development, physical well-being, self-determination, social inclusion, and rights (Badia et al., 2013, p. 108). The context of human functioning and the potential of individuals to grow and develop across each of the eight domains makes quality of life obtainable for all people (Claes et al., 2012).

Verdugo et al. (2012) also looked at the systems by categorizing them in the micro, meso, and macro systems of society. The micro section includes social context, such as the family, home, peer groups, and the workplace. This group shapes the level of quality of life established by the 8 indicators. The meso system includes the neighborhood, community, service agencies, and organizations that directly affect the function of the microsystem. Finally, the macro system included culture, socio-political, and economic factors that impact each individual's life (Verduga et al., 2012). In each of these systems, slight changes can impact an individual's quality of life. Leisure education is relevant in all three levels, as society must acknowledge the need for including people with disabilities at the macro level, community and agencies must 
adapt to meet the needs of people with disabilities at the meso level, and finally the individual must have the skills to access leisure activities at the micro level.

Schalock et al. (2016) further explained quality of life by discussing the concept of the moderator and mediator class. These classes take into consideration more environmental factors associated with quality of life. The moderator class includes personal demographic, organization, culture, and family-unit factors, individuals are born to. The mediator class includes personal status, provider system, and community factors which can vary over time, age, and choices. These dimensions impact quality of life and should continue to be studied across environments and cultures (Schalock et al., 2016). Depending on the moderator and mediator classes, quality of life and leisure participation can look very different.

Regarding how to improve quality of life, Verdugo, Schalock, Keith, and Stancliffe (2005) stated, "The first is a shift in focus away from the belief that scientific, medical, and technological advances alone would result in improved life toward an understanding that personal, family, community, and society well-being emerge from complex combinations of these advances plus values, perceptions, and environmental conditions (p. 708)." Harner and Heel (1993) also discussed measuring quality of life by reflecting on human beings around the world as individuals that live their lives within their unique environments. Through this reflection, quality of life will then measure the degree to which people experience a life of quality and personal well-being matching those in their environment (Harner \& Heal, 1993). In a Sydney Roundtable (2004) led by the International Association for the Scientific Study of Intellectual and Developmental Disabilities, measurement became an important topic in quality of life discussions. These measurements included the degree to which people have life experiences they value, the ability to contribute to a full and interconnected life, the context of 
physical, social, and cultural environments that are important to the person, and measured experiences both common to all humans and those unique to individuals. The roundtable also concluded that quality of life is important for all people and should be thought of in the same way for all people, including individuals with intellectual disabilities (as cited in Verdugo et al. 2005).

\section{Quality of Life and Leisure for People with Intellectual Disabilities}

Leisure activities impact the level of quality of life for people with intellectual disabilities. Modell and Valdez (2002) found that participation in a variety of physical and recreational activities can serve to increase enjoyment and quality of life. Social skills and relationships that are formed through similar interests and leisure activities can have lifelong implications. Living independently and having a job enhances personal outcomes (Claes et al., 2012), while unemployment, lack of appropriate community interaction, underdeveloped social networks, and deficit in skills to plan and utilize their free time decreases quality of life (Washington, Hughes, \& Copeland, 2014). Often, quality of life is more related to preference and constraints of leisure participation than the actual quantity and quality of the activity (Badia et al., 2013). Leisure education could greatly impact quality of life for those who do not feel capable of performing an activity but can participate once someone has been shown the activity (Badia, Orgaz, Verdugo, Ullan, \& Martinez, 2011).

Current barriers. The National Organization on Disability (2001) reported, "people with disabilities spend significantly less time outside the home in socializing and other activities, than people without disabilities. They tend to feel more isolated and participate in fewer community activities than their non-disabled counterparts (as cited in Shelden \& Hutchins, 2008, p. 317)." This suggests barriers tend to be a major factor in achieving a high quality of life 
through community involvement and leisure activities. Badia et al. (2011) found both personal characteristics and barriers perceived by the participants significantly influenced participating in leisure activities. A survey of 237 participants with intellectual disabilities showed that personal factors significantly accounted for different levels of participation in activities at home, but not in physical activities. Age significantly accounted for different levels of participation in the types of activities where the youngest participated in more activities in both quantity and variety. Badia et al. also found motivation decreased as participants' age increased. Education and type of school also impacted the level of social skills used to access the community. Participants who were educated at an ordinary educational center participated in more social activities than did participants who received special education (Badia et al., 2011).

Badia et al. (2013) found that disability and socioeconomic factors were not associated with level of participation, but the perception of barriers significantly accounted for the different levels of participation in activities at home and in social activities. They found that reduced participation was due to not having enough time, being tired, being too old, the need to depend on another person to carry out the activity, and the fear of being mocked. Participants that perceived constraints to participation showed low levels of emotional and physical satisfaction (Badia et al., 2013).

Datillo (2012) discussed how low income does influence leisure behavior. Without an income, people are less likely to spend money on leisure, travel, participate in outdoor recreation, exercise, visit zoos, parks, and attend public events. Often poor health is attributed to low income access to resources to provide a healthy life. With poor health and low income, people have less motivation, resources, and ability to access leisure opportunities. Low income is also related to a lack of reliable transportation for many people with disabilities. Without basic 
resources, leisure is not a priority for many of the individuals, families, and outside sources (Datillo, 2012).

Leisure and environment. Leisure depends greatly on the environment in which participants access the activities. Schalock et al. (2010) also described the relationship between the person and the environment as it discussed the fit between a person's state of functioning and the demands of the environment in which the person lives. Schalock et al. (2010) described how a person's functional limitations and the supports available within the person's environments are continuous and changing making decisions fluid over time (Schalock et al., 2010). Schalock et al. (2016) explained "ecological models of disability focus on person-environmental interaction and the congruence between personal competence and environmental demands and opportunities resulting from the interacting factors (p. 8)." The ecological model of disability allows us to plan for the involvement of individuals with intellectual disabilities in varied environments. Reevaluating and assessing environments and fluidity of supports and change should be a continuous conversation instead of a fixed ideology.

Quality of life is also effected by the environment and access to the services found in the community. Verdugo et al. (2005) stated, "the quality of life concept represents the next logical step from the normalization movement that stressed community-based services to measuring outcomes from the individual's life in the community (p. 708)." Outcomes include the ability to have access to leisure participation. Badia et al. (2013) related how physical, social, and attitudinal environments have more influence on leisure participation than disability-related factors (Badia et al., 2013). By examining the individual and environment, Verdugo et al. (2012) looked at the construct between individual and environments as multi-dimensional. Quality of life is both multidimensional and sensitive to environmental conditions and should extend 
beyond where the person lives, works, is educated, and recreates (Harner \& Heal, 1993). The dimensions include the balance between trust and risk of choice for people with intellectual disabilities. However, the type of environment (independent vs restrictive) decides the amount of freedom to make the choices (Brown \& Brown, 2009). The numerous dimensions of environment and leisure participation relies on the services and environmental assessment to accessing opportunities for people with intellectual disabilities.

AAIDD previously described the mismatch between personal competency and environmental demands. This suggests support needs become a necessity to discuss, particularly the types and intensities of individualized supports (Schalock et al., 2010). Claes et al. (2012) investigated supports to identify ways to address environmental discrepancies. Through the Arduin Foundation in the Netherlands (community based program for persons with IDD that embodies the principles of inclusions, self-determination, personal development, and individualized supports), Claes et al. (2012) examined the relative impact of support strategies and environmental factors on quality of life. The Personal Outcomes Scale was administered to 186 people with experience in the field of intellectual disabilities. Findings demonstrated that in addition to client characteristics, support strategies and environmental factors explained a significant amount of variance in quality of life outcomes. Claes et al. (2012) suggested an overall goal to develop natural supports by conducting person-center planning strategies. This approach would allow for personalizing supports without using unnecessary intrusive assistance (Claes et al., 2012).

For staff, providing good support involves education and training, community involvement and engagement, client empowerment, sense of basic security and positive selfesteem, and opportunities for social engagement and interaction (Claes et al., 2012). Verdugo et 
al. (2005) also discussed the importance of support staff. The authors stated, "Traditionally, the quality of one's life has typically been evaluated by others on the basis of social indicators; however, the quality and subjective well-being revolutions and reforms the movement in the field of ID have changed to the way we think about who should be involved. Individuals with ID should be involved directly in the measurement of the QoL and that proxies be used only if necessary. (p. 710)" They recommend to creating an assessment adapted to an individual's level of intellectual function by simplify the wording, provide pictures responses, use interpreters, find alternative assessment, and incorporate technology (Verdugo et al., 2005). All interventions and supports should be aimed at eliminating constraints while facilitating participation in leisure activities (Badia et al. 2013).

Individual choice and self-determination. Schalock et al. (2016) discussed quality of life through a conceptual model that enhance outcomes through strategies that "encompass developing personal talents, maximizing personal involvement, providing individualizing supports, and facilitating personal growth opportunities (p. 4)." Personal involvement is enhanced through self-regulation, autonomy, self-determination, and individual choice (Schalock et al., 2016). Badia et al. (2013) found that the perceptions of individuals with disabilities related to leisure activities showed constraints to participation and lower levels of emotional and physical satisfaction. The preference of performing certain leisure activities and perceived constraints were the most important predictors of the type of activities individuals participated. Choice and preference made a large difference when considering the quality of the activity. Other factors such as age, gender, level of intellectual disability, residence location, and residential placement did not influence participation and quality of life (Badia et al. 2013). 
Brown and Brown (2009) discussed how to use Schalock's Quality of life indicators as a conceptual framework to focus on applying choice to day to day support for people with intellectual disabilities. They state, "choice with own mind rather than the minds around them push them more toward complex opportunities (p. 13)." The choices made do not need to be costly or complex, but allow choice at mealtime, who to live with, what chores to complete, where to go on outings, and other daily activities (Brown \& Brown, 2009). Badia et. al (2013) found that choices needed to be intrinsically meaningful with an opportunity for diversity of activities (Badia et al., 2013). Modell and Valdez (2002) also found that people with intellectual disabilities should have the opportunity to choose to participate in community activities based on a variety of experiences and skills developed during their school years (Modell \& Valdez, 2002). Not only should individuals with intellectual disabilities have the skills to make choices, but also, they must be provided an environment that allows people with intellectual disabilities to express preferences related to recreational activities (Badia et al., 2013). These statements indicate that individuals need time for exploration of community and leisure experiences during their educational years, not only as an educational experience for them, but also for the community as well.

As choice making is considered part of self-determination, examining the different levels of self-determination and leisure participation is important to discuss as well. Nota, Ferrari, Soresi, and Wehmeyer (2007) found a correlation between self-determination and quality of life as it relates to daily activities. The study involved 141 individuals with intellectual disabilities residing in Northern and Central Italy using self-determination skills in choosing activities for daily living. They found that self-determination has been conceptually linked to a more positive quality of life. People attending the day centers seem to have more self-determination in terms 
of choice of activities in which to participate during the day than people living in institutions and even those living in group housing. In the day centers, younger participants showed greater ability in choosing their activities and had more self-determination in their daily activities. The assisted housing group showed more self-determination in their daily activities such as when to get up in the morning and what to wear (Nota et al., 2007).

The conclusions from the findings by Nota et al. (2007) include the statistically significant correlations found among IQ scores, self-determination, social abilities, and quality of life. Self-determination in choosing activities was associated with potential for social integration. IQ scores significantly correlated with self-determination in daily activities, commitments, decisions, and with social abilities (Nota et al. 2007). This study's outcomes varied from the study by Badia et al. (2011) in which disability factors such as IQ did play a role in the level of self-determination, and quality of life.

As choice is frequently used in both literature and practice in a wide variety of areas in the field, it can be assumed it would work as well in leisure education. Quality of life, selfdetermination, and integration into communities is becoming more investigated as an outcome in education. Choice initiates the self-determination process and prompts action, but through education the need to teach opportunities could enhance and broaden the familiarity to make an informed choice (Washington et al., 2014; Vandercook, 1991).

Social connections. Social connections are limited for many people with intellectual disabilities when accessing their community. The Multifaceted Lifestyle Satisfaction scale conducted by Harner and Heal (1993) found the evaluation of the mean scores, that individuals with intellectual disabilities are least satisfied with their relationships with friends and the amount of recreational opportunity presented to them (Harner \& Heal, 1993). Leisure activities 
are opportunities for social engagement and interaction (Claes et al., 2012). Through these activities many participants can explore society and exercise their right to community involvement. Natural friendships and acquaintances occur in community activities, making relationships based on similar interests instead of befriending only staff (Washington et al., 2014). Brown and Brown (2009) also discussed how social relationships should be developed beyond trained personnel. Individuals should be allowed to choose friends naturally based on similar interests and reciprocity that is required for a friendship (Brown \& Brown, 2009). Vandercook (1991) recommended systematic provisions of instruction on an age appropriate activity as one strategy to enhance interactions with nondisabled peers during such activities (Vandercook, 1991). Socialization continues to be an important part of educating students with intellectual disabilities.

\section{History of Leisure}

Leisure has evolved over time, with a wide variety of different influences and outlooks found in different time periods. Historically, leisure has included similar characteristics to current leisure practices: time, freedom of choice, and activities related to values. Leisure is intertwined with recreation as recuperation through play, including physical activities, but also reading a book, going to a museum, watching a movie, or dozing in a hammock (Hogg \& Cavet, 1995). The range of activities includes but is not limited to playing games, sports, reading, watching television, outdoor activities, resting, festivals, individual and social entertainment. To be considered leisure, a certain state of mind of ease must be associated with the feelings of leisure (McClean, Hurd, \& Rogers, 2008). 


\section{History of Leisure for All}

McClean et al. (2008) credited the development of leisure as play to recreation while developing positive attributes in children. They connected leisure development to the Greek origins. Plato and Aristotle put great value on developing citizenship in children, including honor, loyalty, and beauty as important parts of character development. Plato's basis of learning and autonomy included leisure through contemplation as the foundation for cultural development. Datillo (2008) discussed Aristotle's expression of leisure as the most complete pleasure. Aristotle's belief that "a state of being in which activity is performed for its own sake" developed the classic viewpoints of leisure. However, Catholicism did not find the same importance for character development in leisure, instead valued developing spiritual attributes to provide guidance and the development of moral behavior. Despite the Catholic beliefs, other educators and philosophers, including Froebel, Rousseau, and Sciller, continued to defend play for childhood education, and development (McClean et al., 2008).

McClean et al. (2008) also found that theories of play, recreation, and instinct promoted the use of leisure activities. The theories of play were based on the idea that activities helped burn excess energy. While the recreation theory was based on how play recharges a person for renewed work with an exchange of physical and mental energy with the change of activity. The instinct theory suggested that leisure and recreation helped develop skills for adulthood making individuals adaptable and intelligent (McClean et al., 2008). Datillo (2008) found that the philosopher's ideas of balance of mind and body to maintain peace within a person translated into today's consideration of leisure activities.

Theories had some impact on the practice of leisure in which they consider the well-being for people in general, but societal viewpoints effected the actual practice of leisure excluding 
groups of people based on wealth and ability. Leisure used to be a preoccupation of the "privileged as the other had no time to spare" (Hogg \& Cavet, 1995, piix). Hogg and Cavet (1995) also found that Greek philosophers looked at leisure as a way to achieve personal growth and social advancement in hopes to reach better ranks in society. Mclean et al. (2008) discussed that the upper class would find leisure activities through art, political debates, philosophical discussion, and learning while having their daily needs met through the employment of slaves. These divisions of social classes and races has led to the exclusion of certain groups of people from leisure activities.

McClean et al. (2008) discussed the value found in leisure activities has also changed in different time periods as seen in their description of leisure throughout history. Leisure was a focus point during the Renaissance period. Painting, music, literature, and science were practiced by many making this time period known for its leisure activities and famous for the cultural contributions. During the Middle Ages, parks and recreation areas became important when developing city planning. In contrast, the American colonial period and the industrial revolution became a society defined by work replacing the value of leisure activities. In America, overall survival became a top priority making leisure a sinful act of laziness. The practice of work during the industrial revolution changed the way society valued wealth and material wants versus leisure activities. The $20^{\text {th }}$ century saw another movement to establish public recreation including the development of national, state, and municipal parks. During the Great Depression, the concern about problems related to lack of leisure and recreation when considering mental health issues became a topic of discussion. Post World War II, an emphasis of physical fitness and environment conservation paved the way for further development of recreation and leisure. The 1960s brought a youth rebellion counter culture movement that 
rejected the norm of political, economic, and educational establishments. The use of leisure and recreation made this time era unique with music, drugs, and alternative lifestyles.

Today, vocational outcomes continue to be a priority as people work for material wants (Datillo, 2008). However, the view of leisure has changed. It is now commonly seen as a need

for all. It no longer is reserved for the upper-class society. These modern views should continue to evolve to include people with intellectual disabilities.

\section{History of Leisure for People with Disabilities}

Documentation of the history of leisure development for people with disabilities is limited, but several movements have promoted leisure for all people. Leisure counselling started after World War II to assist veterans in participating in rehabilitation programs (Joswiak, 1989). The uses then transferred and transformed from injured vets to individuals with disabilities morphing into therapy related activities. This practice did not continue overtime as professionals found that leisure counseling had serious drawbacks. It was short term and could only be delivered 1:1 or in small groups (Joswiak, 1989).

Legislation in the 1970 s addressed the need to provide recreation and leisure services to individuals with disabilities. The Education for All Handicapped Children Act of introduced therapeutic recreation as a related service for persons with disabilities. During this time, therapeutic recreation was "devoted to facilitating the development, expression, and maintenance of appropriate leisure lifestyles for individuals with physical, mental, emotional, or social limitation" (Schleien, Meyer, Heyne, \& Brandt, 1995). During this time period, state developmental disabilities plans included recreation and leisure as a priority area for children and adults with developmental disabilities. The President's Committee on Mental Retardation included recreation/leisure/social skills instruction as 1 of its 10 priority areas. These reforms 
were initiated as many individuals returned to their communities as deinstitutionalization occurred (as cited in Schleien et al., 1995). Hogg and Cavet (1995) also discussed the 1970s movement as a change in policies created therapeutic recreation as a related service for individuals with disabilities. The deinstitutionalization process needed appropriate recreation and leisure as both therapy and time consumption (Datillo, 2008). Current trends in physical education programs shows a shift in educational priorities to reduce the physical education programs (McLean et al., 2008).

More recently, Kleinert, Miracle, and Sheppard-Jones (2007) conducted an online survey of teachers and students with moderate and severe intellectual disabilities to determine how often students were included in in both school and community activities. They found that students with disabilities were included across a wide range of both school and community extracurricular and community activities including church, 4-H, choir, school clubs, and social activities outside of school. This survey also included the types of supports needed in the environment including parents, special education teacher, general education teacher, and peer support. They found the primary supported was their parent or family. However, the survey did not take into consideration individual responses, which prevented and accurate percentage of students who participate with a type of support to be calculated.

\section{Leisure Education Development in Regular Education}

Leisure education in regular education is disguised using many other terms such as extracurricular, physical education, enrichment activities, after school programs, performing arts, and athletics. With these broad terms, researching and creating a leisure education program has proven challenging with a few questions. What should we be considering leisure education? What are the past practices related to leisure education? 
Reardun and Mundy (1984) discussed the importance of leisure education from a holistic viewpoint. They compared the amount of time people have in non-work years versus work years and in non-work hours versus work hours. Potentially, unfilled time leads to boredom and discontentment, which in turn lead to discussing the importance of preparation not only for their career, but also for leisure activities. Many assumptions have been made that people should just know opportunities, but that has not been the case. Leisure requires knowledge, awareness, and skills that include recreation and leisure activities (Reardun \& Mundy, 1984).

Leisure education has been very limited in K-12 schools. Reardon and Mundy (1984) broke down the different age levels to discuss the types of leisure education that is important to address. During the elementary school years, students need to become aware of and develop positive attitudes for a wide range of leisure-related activities, events, and experiences. During adolescents, students should increase independence and need to be able to explore and implement leisure choices. These opportunities should happen in school and extracurricular activities, peer and family influences, and non-school organizations. However, leisure education has been most successful within community-based recreation and leisure services programs rather than K-12 public school programs.

Reardon and Mundy (1984) discussed some problems with K-12 leisure programs. They stated that there was a misunderstanding of leisure as both a concept and as a process. They found that leisure activities were not viewed as skill development in attitudes and values. Leisure instead was being viewed as outside the role of the school when considering curriculum development. Reardon and Mundy did state that some aspects of leisure were found in career education. 
In a position paper, Leisure Education in Schools (2012) discussed in great length the importance of leisure education for all grades. The authors felt that the goal to leisure education is to obtain the necessary recreation participation skills. Part of these skills is to recognize the different opportunities available during leisure time, learn to make decisions based on their own personal happiness, health, and strengths. These opportunities should include a broad range of activities such as music, theater, sports, outdoor pursuits, and others that involve creativity, strategy, and much more. Social contexts should be considered when making friends, learning through team competitions, and finding activities for all individuals. Sometimes community resources such as parks, museums, and cultural centers can provide unique opportunities for student growth (“Leisure Education”, 2012).

Leisure Education in Schools (2012) recognized that leisure education is an important part of personal development and lifelong learning process. Over the last 80 years, leisure education's relationship with the public schools have progressed from one facility providing instruction to infusing curriculum into current programs, and then to the revival of after-school programs. In all areas, leisure was linked to personal growth. However, improvement need to happen to continue progression in school curriculum, training leisure educators, creating formats and context for program ideas, time constraints, and deficits in school budgets ("Leisure Education”, 2012).

The position the contributors took also discussed the rationale in including leisure education in schools. They found that free time is a cause for a lot of the problems of today's youth. They linked free time to delinquency, violence, alcohol and drug use and abuse, sexual activity, and obesity due to the lack of productive activities. The sensation seeking, excitement, and belonging led to making poor choices related to the use of free time. With boredom and 
limited leisure exposure, the need of leisure education to reduce these risks and add strengths through leisure and recreational activities become important in assisting youth to living healthier lives (“Leisure Education”, 2012).

Finally, physical education has some leisure education ties but does not encompass leisure education. However, physical education is currently required in school districts. McLean et al. (2008) reported that the President's Council on Physical Fitness and Sports (1956) helped upgrade the fitness of the nation's youth by promoting sport participation and public awareness of fitness needs in school and community-based sport and fitness programs. The effort continued in the 1990s with a President's Challenge Physical Fitness Program to improve state and federal goals and guidelines, set up school championships, and encourage participation in fitness awards. Wallhead, Garn, and Vidoni (2014) found that the purpose of physical education was to expose and teach many types of sports or physical activities to help promote a lifetime of health and wellness. Physical education used to intrinsically motivate students to perform similar activities into adulthood. However, adult participation and the transfer of motivation has decreased. Brown, Nobling, Teufel, and Birch (2011) found that many students were overweight due to less physical activity. Physical after school activities have been replaced by TV, video games, and computer leading to a less active lifestyle.

To incorporate leisure education into classrooms, examining school sports, performing art programs, fine art clubs, and other extracurricular clubs and activities becomes important to the success of students. In 2005, half of all students in elementary and middle school who attended after-school activities in the US either participated in a sport or music program (Simpkins, Vest, $\&$ Becnel, 2009). Continuous support is needed to continue these programs and to develop high quality after school programs to combat the risks and the inactivity of the youth. Delegating the 
responsibility of leisure education to trained teachers can help develop activities into courses, curriculum, and after school programs. Leisure education is necessary for all students and has not been naturally absorbed in other life areas.

\section{Leisure Education Development in Special Education}

Datillo (2008) found that the deinstitutionalization process led to the development of more leisure opportunities along with the development of different educational practices. The lifelong educational process has become an integral part of family, school, and community life. Services changed to be directed as more holistic and thus included leisure education. Leisure education refers to the use of educational strategies to enhance a person's leisure lifestyle. Datillo (2012) defined leisure education as, “an individualized and contextualized educational process through which a person develops an understanding of self and leisure and learns the cluster of skills necessary to participate in freely chosen activities which lead to an optimally satisfying life." (p. 269). Leisure education is beneficial to all but especially important for those who have barriers to participation and often large amounts of free time. With a lack of knowledge, skills, abilities, and awareness, a person may see free time as unfulfilling and often harmful to quality of life (Datillo, 2012). Leisure education should include teaching various recreation and leisure related skills including attitudes and values. Leisure education should simply be a process designed to facilitate maximal leisure well-being. Leisure education should be an individualized process where understanding of self and free choice is promoted (Datillo, 2008). The lack of self-direction to fill free time leads curriculum development in leisure education to consider these skills: how to pick leisure activities, why we should participate, and where can these activities take place (Joswiak, 1989). 
Because of its connection to quality of life, leisure should be considered in education. Even with the development of leisure, much more time and energy was placed in the 70s-80s creating curriculum and programming to promote employment as society valued material wealth instead of program promoting well-being. McDonnell, Hardman, and McDonnell (2003) discussed different incentives for vocational education. In 1982, vocational education became a priority as many teachers looked to teach skills through a longitudinal sequence to those with severe disabilities. The idea of transition to work became a dominant movement in education. The Office of Special Education and Rehabilitative Services developed a framework for improving post school employment outcomes. Federal legislation developed the Rehabilitation Act with amendments in 1992 and 1998 promoting work outcomes. Programs such as Ticket to Work, School to Work Opportunities Act of 1994, and Work Incentive Improvement Act of 1999 continued to promote vocational education in the school districts (McDonnell et al., 2003). These initiatives have not solved the complex issues of employing people with disabilities or teaching leisure skills to fill free time.

Mithaug et al. (1985) stated that leisure education was often omitted; a priority placed on vocational training resulted in a loss of instruction in social and independent living skills. For a complete transition out of high school, Bedini, Bullock, and Driscoll (1993) defined transition "as independent functioning within the community, especially in relation to leisure pursuit (p. 71)." Often community participation is much more than holding a job, but also becoming a part of the community through recreational activities.

Several researchers have addressed the components of a successful leisure curriculum. Bedini et al. (1993), stated, "the school system needs to teach them how to enjoy and use their leisure (p. 72)." They also state that leisure education has the potential to address functional 
transition needs of individuals. Vandercook (1991) demonstrated the effectiveness of teaching functional skills to students with severe disabilities through direct instruction to be initiated, used, and maintained in different settings. Vandercook (1991) examined teaching leisure skills through direct instruction by using a task analysis of steps of each skill. The goal of the study was to promote generalization and maintenance along with social skills while completing leisure activities. Vandercook used many best practice strategies that continue to be effective; using natural cues, fading prompts, teaching individual steps of a task analysis, programming common stimuli, and attaining fluency. Social skills and interactions were also an important part of developing leisure skills. The conclusion of the study showed an increase in the use of skill and interactions with regular education peers.

A more comprehensive curriculum by Wake Leisure Education Program (1990) addressed perceived leisure related needs of students with severe disabilities in transition. The curriculum was based on Bandura's (1977) self-efficacy theory. The curriculum's ten units include: a) leisure awareness, b) self-awareness in leisure, c) leisure opportunities, d) community resource awareness, e) barriers, f) personal resources and responsibility, g) planning, h) planning an outing, i) the outing, and j) outing evaluation. In these units, social skills were addressed through modeled behavior, practicing behavior, and receiving feedback.

Bedini et al. (1993) evaluated the Wake Leisure Curriculum and found that leisure education improved understanding of the value, increased ability to identify a wide range of activities, increased initiation of leisure activities with friends and family, development of independent planning skills, increased assertiveness with family, and increased confidence in decision making. From the experiment, both family members and teachers felt that leisure 
education was important. Finally, the researchers found that leisure education curriculum in public school had a potential for increasing leisure wellness.

Kleinert et al. (2007) conducted an online survey of teachers and students with moderate and severe intellectual disabilities to determine how often students were included in in both school and community activities. They found that students with disabilities were included across a wide range of both school and community extracurricular and community activities including church, 4-H, choir, school clubs, and social activities outside of school. This survey also included the types of supports needed in the environment including parents, special education teacher, general education teacher, and peer support. They found the primary supported was their parent or family. However, the survey did not take into consideration individual responses, which prevented and accurate percentage of students who participate with a type of support to be calculated.

Other research has shown that adaptive physical education also has an opportunity to contribute to leisure education. Cowden, Wright, and Grant (1984) discussed the importance of adapted physical education as a result of the case Gary W. et al. vs State of Louisiana. This court case required an enhancement of programming with specific requirements for the treatment and development of educational plans for students with disabilities. This addition of services emphasized the change of recreation and leisure services. The class action suit was based on the premise that "Each child had a constitutional right to treatment that afforded him a reasonable chance to acquire and maintain those life skills that enable him to cope as effectively as possible as his own capacities permitted with demands of his own person and of his environment and to raise the level of his physical, mental, and social efficiency, (p. 98)." As a result, adapted physical education should include more evaluations with specific criteria in mind. The major 
objective of developing adaptive PE was to use assessments to determine client's ability to structure his own leisure time after school or work, weekend, and free time at home. The other objective was to have class members and families determine recreation and leisure interests and to know resources available in the community (Cowden et al., 1984).

The combination of the Education for All Handicapped Children Act in 1975 and the class action suit began the development of different approaches of implementation in the Individualized education plan. More recent literature by Krueger, DiRocco, and Felix (2000) discusses how adapted physical education specialist should also assist in the development of Leisure transition plans. They state, "APE specialists need to concentrate on activities in the community that promote physically active lifestyles while enhancing health and wellness of students with disabilities." (P. 222). By age 14, transition services are included in the IEP which express students' needs to prepare for postsecondary education, adult service, independent living, development of employment, objectives and community participation. Adapted physical education specialist should concentrate on community participation in the area of the transition section by promoting and addressing programming needs in physical activities and leisure skills.

Krueger et al. (2000) go on to discuss how the leisure transition plan should be included in the transition process with specific goals. The major goal would be to systematically teach how to use free time, how to perform recreational activities, and be responsible for making choices for free time. These choices should also be connected to community resources and opportunities while determining activity interests, preferences, and needs. Once these activities are included into the physical education curricula, assessing skill levels and preferences help determine the opportunities for likely participation after graduation. Many times, the lack of experience and skill development to sue community resources and facilities prevent active 
participation by individuals. By creating these assessments, opportunities, and skill development, transition to adult life is smoother with previous experience in navigating community opportunities.

The study on adaptive physical education professionals by Krueger et al. (2000) showed a disconnection of services and transition plans. They reported that $21 \%$ of adaptive physical education professionals have written and Leisure Transition Plan. Most times the Adaptive physical education's role was misunderstood where $64 \%$ of the individuals were excluded from the transition process. 41 percent of the individuals were not aware of their role, and that a lack of collaboration created conflicting roles, difficulty in finding common plan time, and overloaded work schedules prevented effective transition plans. Overall, they found that the lack of professional development resulted in the loss of awareness of roles, key legislature, overall goal of programming, and effective assessments which prevented a program that could assist in overlapping recreational and leisure skills into the community section of the transition plan. The potential of using adaptive physical education as one approach to leisure education is evident in this study.

\section{Curriculum Development}

Curricular development processes are largely based on underlying values. As societal views on people with intellectual disabilities have changed, new approaches to curricular development have evolved. In this section, I will provide a brief overview of some key models and then discuss the current prevalent model of an ecological approach in more detail.

Curriculum development has been approached from many different directions with many different ideas on the content to teach. Curriculum development does not always focus on holistic outcomes. Often, leisure outcomes have been forgotten, but responsible use of free time 
is important for any person to learn. From an early age, play brings happiness, enjoyment, and contentment. Constructive use of leisure has reduced stress by improving physical and mental health (Joswiak, 1989). Students have a large amount of free time after a structured school day. Yet, most students lack self-direction to use the time meaningfully. Teaching skills to fill free time meaningfully should include what to do outside of work or school, extracurricular activities with peers, activities to do alone at home or in the neighborhood, and events with family and

friends in the community. Teaching individuals with disabilities how, why, and where to leisure can contribute to the development of healthy play behavior and stimulus (Joswiak, 1989).

Deciding skills to teach becomes an important concept to consider when developing curriculum. Models of Curriculum Development for People with Intellectual Disabilities

Over the years, educators have used different models in developing curriculum for students with severe disabilities. As all individuals have different strengths and ways of learning, educators have faced many challenges associated with meaningful curriculum. McDonnell et al. (2003) reviewed different types of models that have contributed to the educational system. The institutional model guided teachers to provide, care, and protect people with disabilities. They provided treatment plans to "cure" the disabilities. Often, therapeutic rehabilitation and education involved leisure activities (Hutchison \& McGill, 1992). However, assumptions that individuals with disabilities could not learn; and individuals were found to be threats to society prevented inclusion and development of meaningful programming (McDonnell et al., 2003).

The eliminative model was developed based on the belief that for a teacher to teach and a student to learn, inappropriate and undesirable behaviors would have to be eliminated from a person prior to being taught additional skills. The process was intended to help choose 
educational interventions. Because of changes in curricular trends, functional behavior assessments and analysis became more useful. With further research, the method of intertwining curriculum with behavior management has proven to be more effective (Shelden \& Hutchins, 2008).

The developmental model during the 1960s and 1970s focused on training and educational instruction to be the same as nondisabled peers. The educational objective included cognitive, communication, social, motor, and self-care. The problem with this approach was found in mastering all the prerequisite developmental skills (McDonnell et al., 2003). The sequence training objectives trapped presumed prerequisites rather than connecting task to important adult tasks. Skill development should take into consideration the value of teaching prerequisite skills versus moving towards a more meaningful skill acquisition. In this consideration, component skills and complete activities became competing ideas. The skill development for tomorrow's benefit should continue to drive instruction (Wilcox \& Bellamy, 1987). Without the prerequisite skills, a wider range of skill development was prohibited. Often, people with disabilities did not learn how to access the community (McDonnell et al., 2003). This realization pushed teaching into a new area of functional activities such as counting money in a grocery store. Teach full activities or alternate performance strategies (counting money vs. debit vs dollar more) became viewed as more effective and useful to creating more opportunities of independence. Teaching the core skills allowed usage of skills in multiple ways (Wilcox \& Bellamy, 1987).

The ecological approach to curricular development is founded on a set of core values about inclusion and opportunity for individuals with intellectual disability. Shelden and Hutchins (2008) identified those values to include facilitate meaningful participation, combine 
individual and family supports, and focus on outcomes. The ecological approach also reflects values of community participation and interaction with individuals with and without disabilities. Identifying communities and unique family cultures is also a value that is a high priority for curricular development. Shelden and Hutchins (2008) also identified the importance of the individual's own respect and self-determination when making educational decisions.

We do not have a body of research examining the efficacy of the ecological approach. However, the approach is widely enough accepted to be presented as the suggested model in many methods textbooks related to educating learners with moderate and severe disabilities. The system of creating an ecological approach includes these characteristics: a) outcome-based, b) longitudinal, c) meaningful, d) community-referenced, and e) age appropriate. Through this process meaningful short term and long-term goals can help direct meaningful curricular development (Shelden \& Hutchins, 2008).

The ecological model focused on opportunities to participate in the social and recreational life of the community. This model led to the process to individualize curriculum, create person-centered planning options, and make each plan unique. Strategies were developed and created into the menu of services, natural supports, and choice (McDonnell et al., 2003). Conducting ecological inventories along with prioritizing skills helped prepare people for performance in natural environments, allow for effective and efficient instruction that is meaningful to each student, and teaching skills that are valued and respected by each culture (Wilcox \& Bellamy, 1987).

Shelden and Hutchins (2008) discussed the importance of deciding what should be taught to individuals during curriculum development. This individualization is especially important as decisions are made for education in which a map of curriculum goals can turn into meaningful 
outcomes. To obtain meaningful outcomes for people with disabilities, individualized or personalized curriculum can assist in focusing on specific and unique learning objectives that are meaningful to the individual (Shelden \& Hutchins, 2008). The prioritization of curriculum development should include the area of leisure education.

A similar approach to curriculum development was discussed by Ryndak and Alper (2003) as a blending process which entails selecting goals and skills that will benefit current and future environments through person-centered planning. The IEP team determines relevance and importance identifying curriculum contact that reflects values with the best information possible. This approach also includes teaching skills including functional and academic in an inclusive environment. Promoting independence in both inclusive setting and adult life begins with participation with peers. To do this, Ryndak and Alper suggest through person-centered planning gather information to prioritize functional needs, utilize family input, create a personal profile including home life, community activities and work, develop general education curriculum, consider future hopes and dreams, discuss functional needs, priorities, peer involvement, community inventory, related services, assessments, and records (Ryndak \& Alper, 2003). Verdugo et al (2005) links quality of life with person-centered planning when they state, "Increased interest in the quality of life concept and its measurement is the rise of the consumer empowerment movement and its emphasis on person-center planning, persona, and valued outcomes and self-determination (p. 708).”

In conducting studies on interventions for leisure skills, researchers chose to teach certain skills differently. Most of the past research did use some form of systematic instruction to teach skill acquisition, but chose the skills to teach by using methods such as student's preference, peer preference, promoting inclusion, personal choice, or no indication. 
Helps and Herzberg (2013) chose to teach how to navigate and access preferred activities on the IPad 2. They taught a single student how to access activities such as movies and songs. These activities were preferred leisure activities that intrinsically motivated the student as indicated by an interest inventory. Wall, Gast, and Roysen (1999) allowed self-selection for instruction on beanbag toss, indoor putting green, croquet, jenga, checkers, a Walkman, or Uno. They chose these activities based on participant preference, IEP team, and consultation from parents, guardians, teachers, and paraprofessionals. Wall and Gast (1997) chose to instruct on Uno, croquet, and horseshoes based on pre-investigation of student preference, consultation, and age- appropriateness. Cannella-Malone, Miller, Schaefer, Jimenez, Page, and Sabielny (2016) used a leisure inventory and chose the $1^{\text {st }}, 3^{\text {rd }}$, and $5^{\text {th }}$ ranked tasks to teach. They included air rockets, art portfolios, basketball, bubble gun, darts, dominos, lite-brite, Mr. Potato Head, nail polish, origami, puzzle, selfie, silly selfie, and weighted curls.

Yilmaz, Konukman, Birkan, Ozen, Yanardag, and Camursoy (2010) used constant time delay teaching swimming to students with autism. They targeted swimming because research has indicated children with autism have an interest in swimming and because swimming was found enjoyable and popular with children their age. They also felt it was relevant as it can be used as a therapeutic resource for development of motor and social skills. Another study that used peer preference was conducted by Carlile, Reeve, Reeve, and Debar (2013) where they taught leisure activities to students with autism using an activity schedule. They chose the leisure activities based on the preferred activities of 12 general education students. These activities were presented to the individuals and then were chosen if $50 \%$ of the individuals selected the activity out of 15 . These activities included nerf basketball, air hogs Heli blaster, table top pinball machine, perplexus, spinning tops, paper jamz drums, kerplunk, frisbee golf, 
Crayola color, slinky, pin toy, hot wheels matchbox cars, hot wheels monster trucks, remote control car, and Beyblade metal fusion.

Pence and Dymond (2015) wanted to promote participation in extracurricular in accordance to IDEA and the equal opportunity clause for participation. They choose school clubs, organized sports, and creative activities. These clubs were chosen based on student interest and support needs, investigating existing school clubs, completing an ecological inventory of the school club, seeking appropriate support, and addressing learning priorities. Vandercook (1991) also completed an ecological inventory based on the activities that could be found in the student's community. They narrowed down teaching a task analysis of bowling and pinball with least to most prompting. Zisimopoulos, Sigafoos, and Koutromanos (2011) used video prompting and constant time delay to teach internet skills. This task was chosen to promote inclusion and was important to the success in that environment.

Cannella-Malone, Mizrachi, Sabielny, and Jimenez (2013) choose to teach video modeling of physical activities to promote healthy lifestyles and to fight obesity. They choose to reinforce participation with preferred items that were chosen by the student. Blum-Dimaya, Reeve, Reeve, and Hoch (2010) used simultaneous video modeling to teach Guitar Hero. They used a preference assessment to choose an appropriate reward for participation.

As part of prioritizing skills in an individualized plan, Datillo (2012) analyzed the type of content that could be included in leisure education. To enhance the quality of their lives in leisure, the education program should include awareness of self in leisure, appreciation of leisure, self-determination in leisure, decision-making skills, knowledge and utilization of resources, social interaction skills, and recreation activity skills. The delivery of content can be delivered in leisure education course, community support through leisure coaching, and family 
and friend support for leisure participation. The goals of leisure education should include promoting health, decrease stress, increase satisfaction, contribute to development, enhance lives, and decrease boredom. Developing reasonable adaptations and accommodations and considering partial participation can assist individuals with intellectual disabilities access a wider variety of activities (Datillo, 2012).

This approach sounds very beneficial, but there are aspects of delivery that create challenges for teachers. The delay involves the lack of innovation and lag in developing current forms for an effective ecological inventory for students in all areas of life. With time constraints, teachers experience challenges in collecting enough information, finding effective supports, and creating a meaningful curriculum. With no clear system of gathering information, storing data, and sufficient time, the ability to implement this specific programing is challenging (Wilcox \& Bellamy, 1987).

\section{Individualized Education Plans}

IDEIA explains the purpose of an IEP as a plan for students to "be prepared to lead productive independent, adult lives to max extents possible, promising careers, personal relationships, comfortable homes, and enjoying leisure-time activities. (Washington et al., 2014, p. 260)" Transition plans evolved to assist students in moving from high school to adulthood based on preferences and choice in different domains of living (Modell \& Valdez, 2002). Even though the IEP transition plan states that recreation and leisure should be considered, very little attention is given to leisure education (Modell \& Valdez, 2002). Many adults with disabilities have gone through their physical education experiences without the benefit of transition legislation and implementation and have not developed appropriate skills and attitudes toward community-based physical activity and recreation/leisure. Community sport, recreation and 
leisure participation are areas in which transition planning can make a significant difference in a young person's quality of life (Modell \& Valdez, 2002).

By creating plans and vision statements for IEP purposes, questions such as "What will the student do for fun and recreation?" will be addressed. By including these questions and by valuing leisure activities, action steps can be developed to assist in making leisure a possibility (Washington et al., 2008). Educators must pay attention to students' development of appropriate skills and competencies and must expose their student to a wide array of physical activity/recreation choices (Modell \& Valdez, 2002).

\section{Current Practices}

Much time and effort has been devoted to developing programming for vocational education for people with intellectual disabilities to train and place students in jobs. Many of the strategies used to create vocational interventions and opportunities can also be used to adapt and develop leisure activities. One trend that has proven valuable is person-centered planning in coordination with the transition plan found in the IEP. "By using the ecological inventory model in targeting outcomes, curriculum can be planned carefully from a top-down approach to analyzing the environments, activities, and skills necessary to be successful (Shelden \& Hutchins, 2008, p. 239)." This approach helps plan for prerequisite skills for success in the environment that will be accessed. By using individualized factors in a personalized curriculum, a longitudinal scope and sequence can support individual growth for students. By creating visions statements during student-centered planning, full and equal participation in the community is the outcome for an effective transition program (Shelden \& Hutchins, 2008).

Schalock et al. (2016) also found using the ecological model and assessment to be beneficial when looking to improve quality of life. The authors also discussed the importance of 
positive psychology and international recognition of the rights of persons with disabilities when changing the way in which individuals with intellectual disabilities are viewed in society. They found that strategies such as values-based, person-centered, and systematic approach to services, supports, and outcomes brought the best quality of life to individuals with intellectual disabilities (Schalock et al., 2016). This focus is a broad outlook and overview of a person's life which includes the leisure domain.

Best practice on teaching individuals with intellectual disability also include: systematic instruction with appropriate support to assist in skill acquisition, fluency, maintenance, and generalization. These approaches include whole task, constant time delay, chaining, systematic fading of prompts and reinforces, and explicit instruction of social skills (Shelden \& Hutchins, 2008; Vandercook, 1991). As previously discussed natural cues and natural supports are also important to incorporate in curriculum instruction. Natural cues and supports are particularly important for community based instruction and leisure education. These best practice strategies have been applied to educational areas including academic, functional, vocational, and daily living skills. Leisure education could also be taught using these same principals.

Washington et al. (2014) discussed three basic approaches currently used to include people with intellectual disabilities in existing leisure programs. To begin with, some programs work at integrating people with intellectual disabilities into existing traditional age-appropriate programing. They include individuals by making adaptations, and modifications to current activities. The second method of reverse mainstream has activities set up for people with intellectual disabilities, but recruits and attracts peers without disabilities to participate as well. These activities are more carefully selected with the thought of the individuals with disabilities as a primary focus. The third approach is called zero exclusion in which activities are accessible 
and considered for both people with and without disabilities. These activities allow participation without focusing any specific type of person (Washington et al., 2014).

Despite the approach to including any person, teaching skills to both people with and without disabilities is an important step to leisure education. Exposure to activities and experiences assist students in making choices in the future (Vandercook, 1991). Students with and without disabilities often take lessons in music, sports, dance, and other areas of interest to not only improve their skills, but also to experience an activity to see if it is of interest. Without experiences, making choices on what you like and don't like becomes very difficult. By discussing teaching leisure in schools, new opportunities to experience, socialize, and build connection with peers can be developed to enhance future transition into adulthood.

\section{Recommendations for Improvement}

The literature has revealed that learned helplessness, isolation, and an unhealthy quality of life is the outcome for many people with intellectual disabilities. Much of the literature has also discussed the need to develop skills in multiple domains of an individual's life. In the past, leisure has taken a back seat to other initiatives such as vocational education. However, future development in leisure education and programming have led to recommendations for improvement. The following sums up some of the recommendations found in literature to assist in promoting leisure education.

Schalock et al. (2016) suggested the use of enhancement strategies that encompass developing personal talents, maximizing personal involvement, providing individualized supports, and facilitating personal growth opportunities should be considered when improving quality of life. Brown and Brown (2009) discussed how developing skills for choice and improving self-determination for individuals with intellectual disabilities could begin the process 
of reaching outcomes that would encompass quality of life (Brown \& Brown, 2009). Verdugo et al. (2012) suggested that strategies such as person-centered planning, individualized supports, and involving the person with a disability in the decision-making process also promotes the selfdetermination and the wanted outcomes for quality of life (Verdugo et al., 2012). Claes et al. (2012) and AAIDD also found that person-centered planning and the assessment of supports needs should be aligned with desired personal outcomes in relationship to person-environmental interactions (Claes et al., 2012).

For leisure education, Modell and Valdez (2002) suggested carefully planning for and developing a wide range of community sport, recreation, and leisure activities to enhance the depth of participation. From the increased activity, benefits such as fitness and social wellness develop. The authors also stated that through the process of exposure and development of skills at early ages, lifelong participation is possible for people with disabilities in community activities such as sports, recreation, and leisure (Modell \& Valdez, 2002). The exposure allows for choice in activities based on the individual's interests and strengths.

To facilitate leisure participation outcomes, Modell and Valdez (2002) recommended collecting information from a variety of sources. They found that collecting feedback from participants in community outings helped seek out supports for continuous access. They also found that personal interviews along with a wide range of experiences assisted in knowing the students interest which assisted in planning future endeavors. By establishing the student's needs, interest and abilities, a determination of viable community based programs allowed for functional skills to be taught within the community and curriculum. Other recommendations included facilitating choice, completing recreation and leisure surveys, consider environmental factors, and finding creative solutions to address barriers such as cost of transportation and 
attitudinal issues. With these experiences, participants would be allowed to narrow down their choices based on needs, ability, and preference allowing for meaningful curriculum and outcomes (Modell \& Valdez, 2002).

Finally, Harner and Heal (1993) discussed recommendations for the service providers. They suggest that the focus on developing programming should be to enhance the individual's socialization as well as accessibility to a variety of recreation activities. Additional training in socialization skills would include teaching individuals how to make and keep friends not only among their peers with disabilities but also with the community. The overall goal would be to have the community begin to reach out to individuals with intellectual disabilities in an effort of friendship and equality (Harner \& Heal, 1993).

Verdugo et al. (2012) explained that consideration of quality of life has been expanding to other areas, such as aging, physical disabilities, mental health, special education, chemical dependency, and other individuals who are at risk for social exclusion. Studies are being conducted to include cross-cultural factors along with growing relationships (Schalock et al., 2005). As this topic continues to expand, leisure education should also continue to be a part of the discussion with hopes to improving quality of life not only for people with intellectual disabilities, but also any other person who exercises their right to community involvement. Overall, quality of life is increasingly seen as "a conceptual framework for assessing quality outcomes, a social construct that guides quality enhancement strategies, and a criterion for assessing the effectiveness of those strategies (Verdugo et al., 2005, p. 715).” 


\section{CHAPTER III: METHODS}

\section{Methods}

The purpose of this study was to examine teachers' perceptions on incorporating leisure curriculum into transition planning for students with intellectual disabilities. Initially, I wanted to conduct focus groups to examine this topic. Krueger and Casey (2000) described the goal of a focus group as the creation of a comfortable and permissive environment. Focus groups assist in continuing discussion, allow for program development, and to continue to gain knowledge on topics of interest. A focus group provides qualitative data, follows a discussion format, and explores a topic of interest.

Due to a small number of potential participants for focus groups, I instead conducted individual interviews. The IRB board approved interviewing individuals based on the same questions that were designed for the focus group. The IRB also approved a change in the recruitment process, allowing me to add a recruitment option through Facebook to search for additional participants that met the predetermined characteristics. Additional changes included procedures to maintain confidentiality.

\section{Procedures for Recruiting Teachers}

Teachers were recruited through three different approaches. The first recruitment was directors of special education teachers. An email was sent to the directors of special education for high school districts within 60 miles of my home location. The directors of special education would recommend teachers who had experience in working with students with intellectual disabilities by sending an invite to participate in the interview. The second recruitment was through the graduate programs of study for teachers of students with multiple disabilities. Programs from Illinois State University and University of Illinois at Urbana-Champaign were 
used for recruitment. Emails were sent to coordinators of the programs asking them to forward a letter of invitation to current and past students. Those of interest were invited to participate in the interview. Facebook was a third option added to recruit more participants. The Facebook post included the same letter sent to the directors of special education and the graduate programs of study. Each participant had to have a degree in special education and experience with working with individuals with intellectual disabilities.

The Facebook post included a letter requesting participation. In the letter, an explanation was given on the purpose of the study and asked for a response by email or phone number. Once participants expressed interest, the approved informed consent form was emailed to individuals to sign and return. All participants preferred contact by phone. Interview dates, times, and locations were then set up according to each participants schedule.

\section{Participants}

The participants in this study were special education teachers who instruct students with intellectual disabilities. Initially, four teachers expressed interest in participating in a focus group. Because that number was not sufficient for a focus group study, revisions were made to the methodology. Once the focus group changed to an interview process, all four of the initial teachers remained interested in participating in this research project. After posting to Facebook, seven additional teachers were initially interested in interviewing. Two teachers decided not to participate after given additional information. One teacher did not meet all the required characteristics. From the 11 teachers who expressed interest, I interviewed eight participants located within 60 miles of my home town. Refer to Table 1 for a summary of participant information. 
Table 1

Participant Information

\begin{tabular}{|c|c|c|c|c|c|c|c|}
\hline Name & Age & $\begin{array}{l}\text { Years } \\
\text { Taught }\end{array}$ & $\begin{array}{l}\text { Life Skills } \\
\text { experience }\end{array}$ & Degree & $\begin{array}{l}\text { Grade } \\
\text { Level }\end{array}$ & $\begin{array}{l}\text { Adapted } \\
\text { PE }\end{array}$ & $\begin{array}{l}\text { School } \\
\text { Setting }\end{array}$ \\
\hline Kim & 36 & 14 & 10 & $\begin{array}{l}\text { Bachelor's } \\
\text { Moderate Severe } \\
\text { Multiple } \\
\text { Disabilities } \\
\text { Master's Special } \\
\text { Ed }\end{array}$ & $\begin{array}{l}\text { Middle } \\
\text { School }\end{array}$ & Yes & Urban \\
\hline Molly & 44 & 15 & 15 & $\begin{array}{l}\text { Bachelor's } \\
\text { Special Ed } \\
\text { Master's School } \\
\text { Administration } \\
\text { Transition } \\
\text { Certificate } \\
\text { Multiple } \\
\text { Disabilities } \\
\text { Certificate }\end{array}$ & $\begin{array}{l}\text { High } \\
\text { School }\end{array}$ & No & Urban \\
\hline Emily & 36 & 14 & 4 & $\begin{array}{l}\text { Bachelor's } \\
\text { Elementary Ed } \\
\text { Master's Special } \\
\text { Ed }\end{array}$ & $\begin{array}{l}\text { High } \\
\text { School }\end{array}$ & No & Urban \\
\hline Sara & 34 & 11 & 2 & $\begin{array}{l}\text { Special Ed LBS1 } \\
\text { Reading } \\
\text { Endorsement }\end{array}$ & $\begin{array}{l}\text { Middle } \\
\text { School }\end{array}$ & Yes & Rural \\
\hline Krissy & 39 & 18 & 7 & $\begin{array}{l}\text { Bachelor's } \\
\text { Special Ed LBS1 } \\
\text { Master's } \\
\text { LBS2 Behavior } \\
\text { Certification } \\
\text { Vocational } \\
\text { Coordinator } \\
\text { Certificate }\end{array}$ & $\begin{array}{l}\text { High } \\
\text { School }\end{array}$ & No & Rural \\
\hline
\end{tabular}

(Table Continued) 


\begin{tabular}{lcllllll}
\hline Name & Age & $\begin{array}{l}\text { Years } \\
\text { Taught }\end{array}$ & $\begin{array}{l}\text { Life Skills } \\
\text { experience }\end{array}$ & Degree & $\begin{array}{l}\text { Grade } \\
\text { Level }\end{array}$ & $\begin{array}{c}\text { Adapted } \\
\text { PE }\end{array}$ & $\begin{array}{l}\text { School } \\
\text { Setting }\end{array}$ \\
\hline Megan & 32 & 10 & 10 & $\begin{array}{l}\text { Special Ed LBS1 } \\
\text { Master's } \\
\text { Teaching and } \\
\text { Leadership }\end{array}$ & $\begin{array}{l}\text { High } \\
\text { School }\end{array}$ & Yes & Rural \\
Casey & 42 & 17 & 9 & Special Ed LBS1 & $\begin{array}{l}\text { Middle } \\
\text { School }\end{array}$ & Yes & Rural \\
Maggie & 31 & 5 & 5 & $\begin{array}{l}\text { Special Ed LBS1 } \\
\text { Multiple } \\
\text { Disabilities } \\
\text { Certification }\end{array}$ & $\begin{array}{l}\text { High } \\
\text { School }\end{array}$ & No & Rural \\
& & & & & & \\
\hline
\end{tabular}

\section{Interview Process}

Once contacts were made and informed consent forms were signed, I visited the participants at a location and time of their preference. I used an IPad to record audio data from the interview. After the interview, I thanked each of the participants for their time. Interviews were between 24 minutes, 48 seconds and 53 minutes, 53 seconds with an average time of 35.32 . I used a semi-structured interview protocol that included open ended questions with follow up questions to allow for flexibility and further clarification. The interview included eight open ended questions with two to three related or follow up questions. These questions addressed viewpoints on leisure, leisure outcomes, values placed on leisure education, current practices, leisure in post-secondary settings, and an opportunity to express any other information, viewpoint, or current practice. After each session, journal entries collected additional information and initial through related to the interviewee responses. See Appendix A for interview questions. 


\section{Security Procedures}

All data were recorded with a password-protected IPad. The IPad may only be accessed by my number lock. The risk of the respondents' information being exposed was minimal. When the IPad was not with me at the interviews or being used to transcribe or code data, it remained in a locked filing cabinet. The digital copies of the data were transferred to my laptop. The computer is password-protected, and I am the only person with the password. All participant names were replaced with pseudonyms. Paper copies of the subsequent transcripts were stored in a locked file cabinet within a secured building when not in use.

\section{Data Collection Procedures}

To gain the perspective of teachers on leisure education, researchers gathered data on current practices and outlooks for future development of curriculum. The questions included defining leisure, leisure outcomes, transition plans, current practices, barriers, team members, value, and future goals. I piloted the interview with a special education teacher who did not meet the predetermined requirements. I requested her feedback about the wording of the questions and structure of the interview. Based upon the answers and feedback provided by the pilot interview, I added and reworded the questions to ensure clarity and accuracy of interview questions. The interviews lasted no more than 60 minutes and were recorded to allow for proper analysis.

\section{Data Analysis}

The interviews were audio recorded to assist in reviewing data. I transcribed the data by listening and repeating recordings until I was satisfied that the typed transcription was accurate for each individual interview. I reviewed transcripts to identify and organize main topics and 
subtopics in the data. I began identifying the main topics and subtopics by highlighting key terms in different colors throughout the data. I then reviewed those topics and subtopics with my thesis chair, who had also read all transcripts. I then returned to the transcripts to sort data into topics and subtopics. I then reviewed each highlighted area and underlined important quotes and circled additional subtopics. I again reviewed the work with my thesis chair. Finally, I reviewed the data within topics and subtopics to identify themes, agreements, contradictions, and novelties. Notes were recorded on sticky notes to connect main points and to organize contradicting or contrasting statements. I reviewed and revised this work with my thesis chair.

Throughout these phases of analysis, my thesis chair and I analyzed the transcripts independently, reviewing and processing the different emerging topics and themes. We came together to discuss discrepancies and to finalize the resulting themes. Transcripts were reviewed repeatedly to ensure correct interpretations. Once the results were deemed an accurate interpretation of the data, I further made sense of the data by organizing the different approaches into a visual representation of a model of leisure curriculum.

Member checks comprised of a description of the findings, the visual model of leisure curriculum, and all quotes used by each member with a short summary of interpretation. This information was sent electronically to ensure that the results matched with the ideas that were conveyed during the interview. A follow up call occurred after each participant had the opportunity to read over the information. The phone call allowed for further discussion on the themes, clarification on certain statements, and allowed for the participant to ask any remaining questions. Once the information was declared an accurate portrayal, I reviewed and interpreted the findings. 


\section{CHAPTER IV: ANALYSIS OF DATA}

\section{Analysis}

Respondents reported their viewpoints on leisure education in relationship to leisure outcomes and current practices with students with multiple disabilities. They were asked questions including: What is leisure? What are students' leisure outcomes? What is the leisure curriculum that is used in your placement? Data from the interviews will be presented in the areas of: a) personal definitions of leisure, b) leisure outcomes, c) current assessment in leisure education, d) curriculum development addressing leisure outcomes, and e) outside influences that direct leisure outcomes.

\section{Personal Definitions of Leisure}

When asked to define leisure, participants struggled to describe leisure in specific and concise terms. However; these themes were present in their responses: a) personal values, b) meaningful friendships, and c) benefits gained from leisure. Their definitions most closely followed the ideas of quality of life.

Personal values. Respondents discussed personal values in relation to experiences both in their personal life and in their students' lives and the purpose behind leisure activities. All respondents defined leisure in relationship to time and enjoyment. Maggie, Megan, Sara, and Kim included the dimension of time in their definition. These responses included the utilization of free time, in contrast to free time not being a part of a structured routine. Personal time was discussed both in relationship to their own free time as well as a student's free time. Responses also defined leisure in relation to pleasure, fun, or enjoyment. Maggie linked leisure to a form of recreation or hobby that brings pleasure, leading to a fulfilling life, while Megan, Emily, Krissy and Sara were less specific by simply defining leisure as anything enjoyable or fun in their lives. 
In defining leisure, participants also identified specific characteristics of leisure activity. Megan linked leisure to performance of an independent activity, and Sara included choice in her specific definition. Krissy and Molly included socialization or friendship with others as a characteristic of leisure activities. Krissy said, "I guess it just depends on the leisure definition, when I'm thinking of leisure, it's just a lot about socialization." Kim, Sara, Krissy, and Megan indicated that leisure had to be in a non-stressful situation, free of pressure. Casey agreed that leisure was a way to relax and have breaks. All participants indicated that it was some sort of activity that occurred both at home or out in the community. Molly linked leisure to a specific setting which was out of their homes and in the community while Kim simply stated leisure occurs outside of a professional place. Descriptions of leisure included a variety of factors, but overall were either general statements or vague.

Friendship. The importance of friendship was prevalent in the conversation about defining leisure. All participants other than Casey discussed different aspects of friendship, including development of relationships, activities involving friendships, and the need to make those connections prior to post-school. Linking friendship to leisure activities appeared to affect many of their ideas about leisure development.

Kim included friendship in her leisure definition. She stated, "I think leisure outcomes would be friendships outside of you know... post school friendships, being a member of your community, an active member in your community, doing you know leisure rec, going to see a movie, going shopping, out to eat, doing all those things in the community that you know families and individuals do, so I think anything for fun and relaxation.”. Kim later commented on the importance of friendship during the high school transition process. She stated, "I think definitely in the high school years it's super important, because you know you are really 
focusing. Post-school is where it is at. Like that's, like that's the end thing right there, you know. It's like friendships are just so huge. You know you want them to have friendships. You want them to have some sort of life outside of school, because I feel that most of the social interactions are happening at school." She then talked about how they relate to students with severe and multiple disabilities when she said, "Kids with severe and multiple disabilities are kind of ... kind of left in the dust in that aspect as far as the lasting friendships."

Molly also included friendships in her definition of leisure, connecting leisure to community participation and natural friendships. Molly said students should be "doing things within their community" and "having relationships with friends and doing what any other typical person of that age would do." She then discussed how family members were the only people taking these students out of the house. Molly's future goals included developing natural friendships as an end result of inclusion.

The discussion on friendship led to the theme of natural and meaningful relationships, both between classmates, and with general education students. Emily, Krissy, Sara, and Molly described trying to create opportunities for natural friendships by fostering interactions between peers through peer programs, peer parties, advocates for awareness, or peer buddies. However, the respondents reported that natural friendships do not often occur in other areas of the school such as unstructured lunch time, outside community activities, or continual participation in the schools. Emily did discuss natural friendship and the importance of friendship between classmates. She stated, "I think being able to get out there and have fun with your friends, and that you hang with other people like you, not like you, you know is really important for our students. It's... It's huge in our ... in our curriculum.”. Emily valued friendship not only in terms of general education peers, but also in the natural friendships that are made with 
classmates. Molly described only one time in 14 years where two students took out one of her students. She stated, "we had a young lady with Down syndrome who was just a ball of fun, we adored her, and she, there were two girls in her PE class that just adored her as well, and they just approached me and said we want to take her shopping, we want to buy her jewelry at the mall, and we want to do this." Since then Molly has tried to create those bonds with regular education peers through buddy systems but has been unsuccessful.

Participants had contradicting viewpoints related to experiences between regular education peers and special education peers. Maggie focused mostly on inclusive experiences. She stated, "I feel like leisure activities help generalize overall communication skills but in a less formal way. And, so kids are able to shine in things that interest them, and hopefully when they are with their peers or their friends in a shared leisure experience, those people also have interests in it. And, I think there is a lot of communication and bonding when you get people together that are liked minded." She then said, "friendships, friendships, I don't know, my kids are so friendly. They make friends wherever you know."

Other respondents found that creating friendship opportunities was difficult. Krissy contradicted, "their same aged peers are like into reality TV or, you know, like, so finding those common interests can be hard." She also identified differences in peer groups. She stated, "So we go to homecoming every year as a group. The difference a lot of standing on the side line when we go to homecoming. Some will get out and dance, you know. They're kind've whatever, but they are very intimidated." In comparison, she described a different dance experience. She stated, "a group of surrounding like life skill students, it was amazing to watch. They had so much fun, and they were so comfortable, and they are around people that have, you 
know, that are just like them." Friendship was a common theme involved in the value associated with leisure despite the different interpretations of natural friendship.

Benefits. In defining leisure, all participants also addressed what they saw as benefits to leisure. All participants discussed different aspects of the benefits of leisure participation. Benefits related to quality of life and health. Quality of life was discussed in terms of fulfillment and life satisfaction. Molly discussed quality of life as some sort of fulfillment. She stated, "if we all just worked and didn't have some fun in our lives once in a while it would be terrible." She then talked about the role of the school in creating fulfilling activities. She said, "I think we take care of a good portion of it (leisure) in the classroom, but it really needs to, we are not going to be there forever, 8 years is a very long time, but it's not forever. And you know, from 22 for the rest of your life, that's a long time. You know, so that's what I would like to see happen at some point."

Health benefits related to both mental and physical well-being were briefly discussed. Sara and Kim both discussed how leisure could help with stress management and anxiety. Sara believed, "it's just a positive, looking for positive ways to relieve that stress, so down the road you don't have to be taking maybe 500 medications," She also discussed how leisure participation benefited social communication and self-awareness. Happiness was also linked to health and quality of life. Kim stated, "I think leisure/rec is more meaningful to me and my life than academics ever have been, you know as far as what makes me happy when I come home from work or school." Quality of life, health and happiness were the main themes when discussing the benefits of leisure education. 


\section{Leisure Outcomes}

Participants discussed leisure outcomes in post-secondary settings. Participants found it difficult to find information on what students were doing after high school related to leisure activities. Related resources, placement, and family involvement were also considered in regard to the influences on the ending outcome. These outcomes were discussed in terms of a) current practices, b) potential negative outcomes, c) placement influences, and d) future goals for further outcomes.

Current. Many of the current leisure outcomes depend on the support, resources, family, and community around the individual. Molly described several of her student's outcomes. She talked about the students that she knew are "actually doing things." She stated, "I have some. I have one boy who gets together... there's a group. Again, they are all kids with disabilities, but like they love like wrestling, and the kids get together. They go like from month to month to each other homes and watch like WWE, and they all get together and they have pizza and that's really cool." She went on to describe one of the students, "he also does camps in the summer time, his parents take him traveling." Other outcomes for her students included eating, movies, and Wal-Mart shopping.

Other participants discussed simple leisure activities due to convenience and the lack of knowledge of different types of activities. Sara and Emily talked about how students mostly chose an IPad to watch YouTube videos or a system to play videogames. She attributed this choice to the structure in the home. She believed parents were in survival mode and think of leisure as "What can I give my kid to keep them busy so I can get my work done?" which resulted in a heavy reliance on technology. However, Sara also said that most of the parents took their kids to community activities such as local trips to the grocery store, swimming pool, or 
summer camp. She felt that families were limited in the opportunities for more complicated leisure activities such as family vacations.

Outside services were discussed, often related to the idea of community resources, availability, level of activity, and the level of parent awareness. Emily and Maggie described how a specialized recreation program was a big asset in the community. Emily stated, "most of my students, if not all of them after they get out of high school are involved in $<$ specialized recreation program $>$ and so with $<\mathrm{it}>$ they are in bowling, they are in games, this summer many of them are in camps, you know, you know for basketball camp, or just many camps of just playing you know with their friends." Emily, Kim, Maggie, and Sara described the importance in the participation in organized sports. Krissy also described activities found in another community specialized recreation group organized by parents, as well as church youth groups, dances, and festivals. Maggie talked about a local developmental disabilities agency and friends first programming, horseshoes, swimming, card games, pets, reading books, music, and dance programs. Kim also talked about other outside agencies such as riding therapy with horses, camps, parks, mini golf, pools, paddle boats, disc golf, and camp grounds. However, she also pointed out that these activities required parent participation to access this type of leisure. These agencies offered a wide range of programming, but barriers prevented individuals from participation.

Potential negative outcomes. Potential negative outcomes became the greatest motivating factors in developing leisure curriculum. Krissy talked about the time after high school without the support team found in the educational system. Krissy discussed one parent's concern when she states "She's definitely worried about his isolation, because that's what happens like he just sits at home. What are you going to do for the next... for the rest of your 
life?" Emily, Megan, Krissy and Maggie discussed the lack of leisure in stating their fear of students becoming sedentary and isolated at home "sitting on the couch", "sitting in front of the television, or sitting behind a videogame". Maggie also stated that leisure is "super important if you don't want them staying at home".

Leisure and free time are often intertwined when discussing the logistics of activities. Maggie made the connection of the relationship of leisure and free time. She said, "the students that I serve have more free time than anyone ever, so it's really important for them to schedule or organize it. Otherwise, they are just going to be stagnant, unstimulated, and bored, and that leads to an unfulfilling life and sometimes behaviors, just because you are just bored out of your mind." Kim echoed the same thoughts when she described her student's outcomes, "I think typically they are not able to work in the community, and so they spend a lot of their time postschool at home, really doing not a whole lot of anything, and because it is a self-contained school they don't get that friendship, those friendships aren't you know made in the school setting, and so I just think that they really lack in that area especially after school." Meaningful activities, quality of life, and friendships were all linked to the way free time was used in post-secondary setting.

Placement influences. Considering future placement became an important topic when discussing potential leisure outcomes. Molly found, "I think if they are in a house again where they are used to going and doing things outside of their home that they will probably continue, but if it possibly is a student that maybe moving into a group home then if that that student is the one that never got out of the house then I think things get a little bit better as far as leisure outcomes for them." She found that group homes scheduled activities as part of weekly routines. Sara also described how parents had to consider day programming after high school for leisure 
activities. Logistics of placements such as funding and transportation were common factors in the decision-making process. Maggie discussed how placement and future instruction was developed based off MAPS meeting to help prepare her students to either living at home or in a group home setting. She stated, "he's got him set up with a group home and a trust that has very specifics, like my child will go on vacation twice a year with someone.” The participants did state that placement did impact their planning of future curriculum for post-secondary outcomes.

Krissy also talked about how important it is to think about placement when deciding what types of activities to teach students. She described the process, "the plan for them, like ultimately, is it to like live at home until they're no longer able to take care of them or will it be more of a group home setting? I'm not sure if I have any that could live in an apartment even with support, I'm not sure that would be a safe option for them. But then just really thinking about what kind've things that they will like."

In contrast, Megan discussed placement by evaluating vocational accomplishments. She hoped that, "they will be competitively employed, hopefully, some maybe volunteering with some support you know from potential job coaches at $<$ adult services agency $>$ or something. Some would be at $<$ adult services agency $>$ and like a day program. And others will unfortunately just probably be at home with mom and dad." Even with these placement options, Megan didn't think they would be doing a variety of activities. She said "Most of our students in their home settings, their leisure activities consist of TV, movies, videogames, like IPad or something, you know, games or apps, things on the IPad of different electronic devices. Some do have computers. Some have Facebook.” Both Megan and Sara also contributed the lack of leisure outcomes to the resources in her community which led to more students' inactivity. 
Future goals for leisure outcomes. Participants did find that leisure education was lacking resources, structures, and research. All the participants talked about future goals and changes that they wanted to make to improve leisure education. However, improvements with leisure outcomes were less prominent in the discussion. One participant, Maggie, talked about developing transition plans through map meetings to make leisure a future possibility. She included travel and transportation in transition plans to prepare for future activities. She developed specific outcomes for each of her community based outings for future participation in similar settings. Maggie worried about her students after they leave high school. She stated, "I don't know how to like check up on them." She was referring to feedback on what they were doing with their lives.

\section{Assessment}

Participants struggled in identifying assessments related to leisure education. However, they did discuss different approaches in assessing students related to leisure activates. The participants found some common themes including a) longitudinal curriculum, b) assessment types, c) ecological inventories, and d) relationship to IEPs.

Longitudinal curriculum. Longitudinal curriculum lacked in many of the respondents practices due to the absence of assessments in the leisure education. Maggie discussed building longitudinal curriculum using map meetings. During these meetings action plans were created in response to many different forms of information. She stated, "we assess and get all the input from others and really it's just the students priorities. Most of my students are able to communicate so they are involved in all that." However, the use of leisure assessments was not practiced. Molly stated that she didn't keep data, but she knew her students. Kim also discussed the use of anecdotal notes when reporting valued activities to parents. The informal assessments 
through observation gave some direction to curriculum development, but creating a longitudinal plan lacked structure.

Megan reported that she didn't use any type of assessment for leisure education, but then she described her practice of using task boxes indirectly related to leisure education. These boxes had different leveling systems based on student performance. These boxes were linked to the essential elements of the common core standards, but did not directly reference the different leisure skills or the assessment that measured level of accomplishment. Kim and Emily also assessed skills indirectly related to leisure by looking at student's communication through the IPad or core vocabulary and the ability to use those words through a hierarchy of physical prompting.

Sara discussed on two occasions the importance of gathering information from interest inventories or anecdotal notes to create a portfolio. This approach assisted the high school level in creating a longitudinal leisure skills between two different building. It was a starting point in knowing what types of activities they were exposed to in junior high.

Assessment types. None of the respondents could name a leisure assessment. However, many of the respondents did talk about the different types of related assessments including preferences, checklists, interest inventories, exit slips, informal assessments, and anecdotal notes. Sara stated her practices, "it's not like.... probably a standard based measurement, but like little checklists, if we are working on like a throwing skill, or a like following directions, a little, basically just like teacher made little, like observations or check lists that I come up with depending on what skill we are working on.” When discussing leisure core skills, her throwing example was the skill most directly related to leisure activities. Krissy also used checklists, but more in the form of an interest inventory based on student's preferences for activities. Sara, 
Kim, Casey, Krissy and Maggie discussed the use of preference assessments or interest inventories for leisure, but Sara and Casey more directly related it to the reinforcement for positive behavior performances.

Maggie said she used the preference assessments and self-assessment, but didn't really have goals for those. Maggie used mostly exit slips to evaluate different activities that students participated not only in her class, but also in the physical education class. Emily also discusses her use of preference assessment when creating leisure activities, but in her practice, parents filled out a back to school packet based on previous experience and knowledge. Megan discussed that they don't have a lot of assessments except for the types the school psychologist uses as an adaptive rating scale. Overall, the participants used a wide variety of assessments and different approaches to leisure activities, but did not have a structured form to measure core leisure skills.

Assessment related to community. Community assessment was an underlying consideration when discussing leisure development. Many of the teachers assessed environments to see what types of supports and activities were available for future participation. This type of assessment steered the development of the types of activities that teachers focused on in curriculum development. Megan stated, "community experiences and leisure activities and things like that fall in those boxes, and so it's always taken into consideration. What are they going to need to do or what are they going to be able to do? What's realistic for them to do when they are not in a structured environment like this." This type of assessment highlighted the importance of placement after high school. Kim also related the assessment of student's assets when planning financially responsible activities to ensure realistic leisure was included in their future planning. Megan assessed the community and categorized the types of activities that the 
kids are most likely to experience such as bowling and going to the movies versus going to a museum or an amusement park. Maggie also assessed the community while gathering information from team during MAPS meetings. These types of considerations directed the skills and supports that were included in transition planning.

IEP goals. Respondents found ways to connect leisure to IEP goals indirectly. Casey talked about how leisure could be written into an IEP. She said, "Obviously just writing goals for it, you know after doing a baseline of taking the kids out in the community and going to the grocery store and seeing some of the struggles that they have, you know, it's not navigating a grocery store, or not communicating with the cashier, or not being able to count money, any of those type things, and it's not grocery stores, so it's not leisure." Emily also described how IEP goals were indirectly related to leisure education. She believed that goals were included in an IEP, in which she responded "I honestly think it's involved in all parts of the IEP. I mean even... even if you have an academic goal, you still could have some type of leisure thing, that the students like to do so you know maybe it's even writing an email or you know, talking communication that's a huge reading goal that you could and writing goal that you could incorporate." Krissy stated that she didn't think that they necessarily had goal in their IEPs related to leisure education, but she then commented later that she though that some of the social skills and communication skills could relate to leisure education.

Megan also described how IEP goals were written in relationship to adapted PE. She stated that "our adaptive PE is more of a rec and leisure class, actually we have talked to other individuals higher up than us about kind of changing the name of it in in our system instead of saying like community based PE, like community based rec and leisure. Because that's how their goals are written as.” Megan later said that the IEP goals are related to more 
communication and to making choices, and not to specific leisure recreation. When writing goals, core leisure skills were not included in IEP planning.

\section{Approach to Leisure Curriculum}

Leisure curriculum is a very broad topic without structure, packaged curriculum, guidelines, standards, or examples which led to many unclear responses. These responses were grouped and interpreted in the following categories a) current leisure curriculums, b) strategies in presenting leisure opportunities, c) core skills versus enhancement skills, i) choice making, ii) independence, iii) communication, iv) social skills, d) curricular research, e) experiences versus skills, f) time vs curriculum, and g) prioritization of course content.

Current leisure curriculum. Much discussion occurred on current leisure curriculum. Krissy and Megan assumed we were talking about packaged curriculum and responded that she didn't know of any curriculum that was specifically leisure, but Krissy felt that leisure occurred in "some components that are built into some of the curriculums." Krissy found curriculum awareness necessary in hopes of developing a cohesive system of delivery. Another important question included was deciding what to teach students. Kim questioned her current practice, she said," is this valuable, am I doing this right?" Casey discussed how unique learning systems had little components such as social skills, academic skills, money management, and time management. Maggie talked about some of the cool apps, DVDs, she used to supplement and visualize leisure settings while teaching some of the enhancement skills such as manners. Overall, detail, programming, and current practices of leisure curriculum was absent from discussion.

Strategies for presenting leisure opportunities. Three areas became apparent when teaching leisure skills. These skills were most often taught in the classroom, community outings, 
or adapted physical education. However, with the three different settings, leisure opportunities lacked a cohesive approach to education. Maggie discussed presenting leisure opportunities primarily based on student's priorities and interests. She said these priorities were addressed both in adapted PE, community leisure opportunities, and in the classroom. She said to address leisure, "is helping like when you think of like executive functioning or like organization basically helping students identify and execute their interests to utilize their free time in a fulfilling way."

Molly described how many of her leisure opportunities occurred in her community based outings. Molly went out 2-3 times a week to a variety of places such as the zoo, bowling, plays, Christmas shopping, restaurants, and movies. Kim had a similar discussion on the importance of community based programs when teaching a wide range of skills. She said, "I don't know how well it's done, as far as like really instructing, like you know, when we go to like a restaurant, we'll try to do dollar over or like pay dollar over or to make your choices, you know your food choices or trying to you know use these pictures to order." She then went on to say that the skills mentioned weren't necessarily leisure skills, but 'there hasn't been a focus on leisure/rec, so I am sure there are a lot of things I should know about and be doing." Kim then talked about curriculum in all areas of life skill. She felt like there was a lot of free time built into the days that could be used for leisure instruction.

Emily, Megan and Sara felt that adapted PE would be beneficial when teaching recreation/ leisure skills. Sara connected some of her leisure curriculum to the games and skills that were needed in physical education. Megan talked about adapted PE in the hopes of renaming it community based rec and leisure, so that it would more accurately reflect the topics that are taught at that time. She stated, "being able to sit down and interact with another person 
to either do a puzzle or play a card game, that is just as important. They can carry that for forever. Who is going to take them out to a track to run?" She felt it was important to have those skilled games sports along with sit down leisure activities. Kim also discussed concern to future development of recreation. She had the experience and frustration of working in a workshop for adults with disabilities where there was "zero expectations, zero instruction, no recreation, you know it's just like wow you know you got all these things happening in school and then they are just left in the dust as adults." Current practices showed that cohesive leisure activities were lacking across different settings of education.

Core skills versus enhancement skills. Participants had limited discussion on actual core skill, but focused much more on enhancement skills found in many areas of education. Core skills that were discussed usually were found in examples that were given when discussing leisure activities. Emily discussed how she taught students to play games by counting out the number of spaces and moving pieces to the correct location. Megan also stated how either her paraprofessional or herself would teach a game that the students have never done before during free time, but it wasn't a planned activity. Sara also talked about the importance of "providing the extra time to show them how to play a game, do a new cooking recipe or something like that." However, she then stated more details about the enhancement skills such as learning how to have a conversation, coping if they don't win a game, or behavior with other adults or students to make friendships. Finally, she made a big comparison of skills needed to teach in vocational education which was an area she understood more clearly. One comment that occurred at the end of the interview after reflection on current practices, Krissy stated how she believed that she does do leisure curriculum, but it wasn't categorized under that label. 
The broadness of leisure core skills also proved difficult to talk specifics. Kim talked about how leisure recreation is very broad leading to the discussion of enhancement skills. She stated, "it can be like so many things. It's like where can you even start accept for the basics like communication, choice making, social skills, I think bits and pieces of that are done." Casey also discussed the enhancement skills when considering the types of skills to include in leisure curriculum. She listed money management, communication skills, self-awareness, selfmonitoring, and transition skill. These areas were more tangible to teachers due to the current structure of curriculum and the ability to include them in many different activities. These enhancement skills were discussed more specifically through choice making, independence, communication, and social skills.

Choice making. Choice making was mentioned by all participants in regards to choosing the activity during free time. Emily discussed how choice making was part of the leisure process. She used Love and Logic to teach students to choose something to do for the day. She related the reluctance to choose due to unknown activities. Her students didn't know what to do, or how to play the game. Megan and Casey also talked about the importance of being able to make the choice in which they incorporated into their unstructured leisure free time. In contrast, Kim made the choices based on the amount of time available and the activities that were occurring during that time. She said she must make the choices of where to go and what to do to ensure that they have recreational opportunities set up for them which gave the activities more structure and direction.

Independence. Participants had a lot of different opinions on this enhancement skill. Megan discussed the importance of having activities that students can complete independently and choosing those skills that can be done without support and on their own. Casey had a similar 
viewpoint. She felt that depending on the game, a lot of kids don't have the fine motor skills to move the pieces, so she doesn't teach that game. Kim talked about the need for more selfdetermination and more independence with enhancement. These needs were more related to regulating their sensory needs to allow for more leisure activity. She stated, "they have to be, you know, given the things like they have to be given the not even making the choice, but like hey I need this compressions vest or I need this sensory bin." She felt that they needed to learn these skills to self-monitor their needs before they can go and access environments.

Kim had a different view point than Megan on the level of independence needed for leisure activities. Kim thought many of her students were going to group homes that included recreation and community outings in the schedule. She felt it was important to focus more on what skills were needed to participate or partially participate in different activities.

Communication. Many participants discussed how communication stretched across all areas of education including leisure education. Emily stated that with the most significant disabilities, learning to communicate and talk with others was a huge goal for leisure activities. She described how she would use the IPad for students with limited communication to teach hi, how are you while using hand over hand or most to least prompting. When asked how should leisure education be included in the IEP, Emily talked about writing emails, and communication as a reading goal. Megan also mentioned that teaching communications was an important part of their program. Kim agreed that communication is the focus for everyone in their placement. She said that it is "a big focus for literally every single kid, 75 kinds in our school are working on those simple communicative goals."

Social skills. Social skill was another topic that was discussed and its importance directly related to the participants' personal value of friendship. Krissy believed that the 
enhancement skills such as social skills were a huge part of leisure education. When discussing future goals, she returned to the topic of social cues as an important area to target. Molly agreed and stated, "you are going to have a whole lot of trouble in your leisure skills if your social skills aren't there." Molly also emphasized the importance of using manners, making friendships, and overall awareness of the people around them. She gave an example of knowing who's turn it is to go through the door and the problem associated with barging and bumping into other people while going through doors. She stated, "I mean all these very simple things, because you're going to encounter that door anywhere you go in the community."

When developing healthy relationships, social skills was also linked to dating and sexual health. Krissy also talked about how social skills are very important especially when acknowledging boundaries with peers of opposite sex. Krissy discussed the importance of knowing social cues and body language. She felt these skills translated into important skills to be addressed in a leisure curriculum. Molly also talked about using sex education curriculum to discuss some of the different types of challenges and relationships. Maggie also mentioned the need for sexual health and relationship curriculum to keep students safe and to lead a normal life.

Curricular research. The holes in research, development, and best practice was discussed when talking about curriculum development. Kim was interested in making changes to include leisure education, but she stated, "definitely more research, more literature on the topic, more you know." She continued, "it's like this big topic. Are we supposed to teach academics or life skills. You know it's either academics or life skills or both. And what mix of those two things do we do, but leisure/rec hasn't gotten into that conversation yet or you know what I mean I think yeah, I think just definitely teacher's needing more directions we need more, we just need more research on it clearly. I mean you know to find out like what are the good 
outcomes and how do we go about obtaining that and you know what are the steps you have to take?"

Maggie talked about the types of research she has conducted. She stated, "I've done a lot of research on like preference assessments, but not like specific leisure things, I mean when we look at systematic instruction, if there's like a leisure skill that my students really need or want, I need to do a better job of finding the research. Like, I was for instances, I was able to, one of my goals for my students was to learn how to swim, not only is it for leisure, but safety, but I was able to find a research article on how to teach students how to swim using like constant time delay, or something like that, it was, it was kind of crazy. You had to like keep data on like your.. your hair bands with rubber bands and it was a little crazy, but it worked, and so I feel like if there are leisure activities that my students want to do, I need to find out the systematic instruction approach that would be most appropriate. And then of course training myself and the people working with my students." This participant was the only person to discuss how to teach curriculum from reading research using systematic instruction.

Experiences versus skills. Many of the respondents focused on exposure and experience with leisure skills as leisure curriculum. Molly and Maggie mentioned the importance of addressing leisure in schools as exposure to a variety of things. Molly described how she had a student with autism that did not like any physical activity, but she took her to a park where walking was required. She recalled, "And I though ok, I know there is benches because I know I am going to get a fit every few feet we walk. And it was a little warm that day, but you know what? She did not say a peep the entire time. We got done, all the way home, that was fun, like that animal, did you see that bear? Did you see.....? I mean those are the things, you know, you liked it out here. And then when I said do you want to do that again next year? She's like yeah." 
A similar experience of trying something new came from Krissy. She stated, "Are they willing I guess even to step out of their comfort zone and try you know a leisure activity that they don't even know that they might you know like. They just think automatically, they'll hate it because they don't have the exposure or the experience." Emily and Kim also said that they wanted to expose and more aware of activities.

Time versus curriculum. When discussing curriculum development, finding out how teacher's use their time is important. The same is applied to the idea of time versus leisure curriculum. When asked about current practices, Krissy, Megan, Kim and Emily talked about how they gave free time as leisure to choose something that they wanted to participate in to fill their time. Krissy states that she didn't have any real practices during that time indicating that the free time wasn't enough for proper leisure curriculum. Emily utilized free time by having time to talk with peers and play board games. She also scheduled Friday's leisure activities out in the community. Kim described her leisure time as unstructured as a way for teachers and paras to take lunch breaks. She describes it as unstructured or a time where they will watch a movie, but not a lot of instruction takes place. Megan talked her practice with free time and leisure education. She stated, "They get to have a little bit more independence in choosing their own activity for that time instead of us telling them what they are going to do. They can also choose the people that they want to engage with and the leisure activity. And then as that group or large group or small group whatever it may be, they get to pick the activity they want to do for that time." Overall, many teachers used free time as a component of leisure curriculum.

Prioritization of course content. The discussion about how the participants prioritized course content brought many different approaches. Krissy talked about how her approach to choosing activities revolved around the idea of future placement. She looked at the skills needed 
to live the most independently in the areas of cooking or daily living, transportation, and money management. She stated, "I used to kind of follow a strict curriculum that went through every month you know things laid out and some of those topics were good to talk about, but we were just starting to get to know my students to see where their needs are and more specifically what are the parents plan." Kim stated something similar. She felt it was important to "make the instruction meaningful for all these different kids."

Megan talked about her reluctance to teach certain leisure skills due to the number of steps needed for an outcome. She described the problems associated with rural school districts and transportation. She stated, "because they have to do that first step [call to order the transportation], to get to the second step, they are not going to complete the second step. They are not going to do the first step." Megan then described her curricular process by setting up task box curriculum that have different differentiated steps related to different areas such as academics, independent living, vocational, common core and essential elements. Her primary focus was completing tasks independently by working through the stages. She also discussed how she was constantly recreating these boxes to address individual's needs.

Casey prioritized her curriculum around behavior education by teaching them how to transit out of preferred activities and using task analysis in making them more aware. She had used leisure time as a motivator to complete work. Casey also placed hygiene as number high priority followed by communication. Maggie prioritizes curriculum based on the MAPS meetings, and inventories. She then placed them into a grid system based on the best way to group students, and the environments that are easily and often accessed over time. She discussed how she would prefer to teach more leisure activities based on an inclusion model and having them participate more in regular groups or activities. 
Barriers. Barriers were brought up in the answers of many questions presented to the participants. This discussion of barriers was directly related to leisure development. Casey stated that depending on the game, a lot of kids don't have the fine motor skills to move the pieces, so she doesn't teach that game. Megan found that the largest barrier was independence. For example, calling and scheduling the bus to attend a leisure activity was a barrier that prevented teaching certain leisure skills. Sara also talked about transportation in relationship to leisure, but her approach included instruction instead of making it a huge barrier. 
Visual Representation of Leisure Education Development

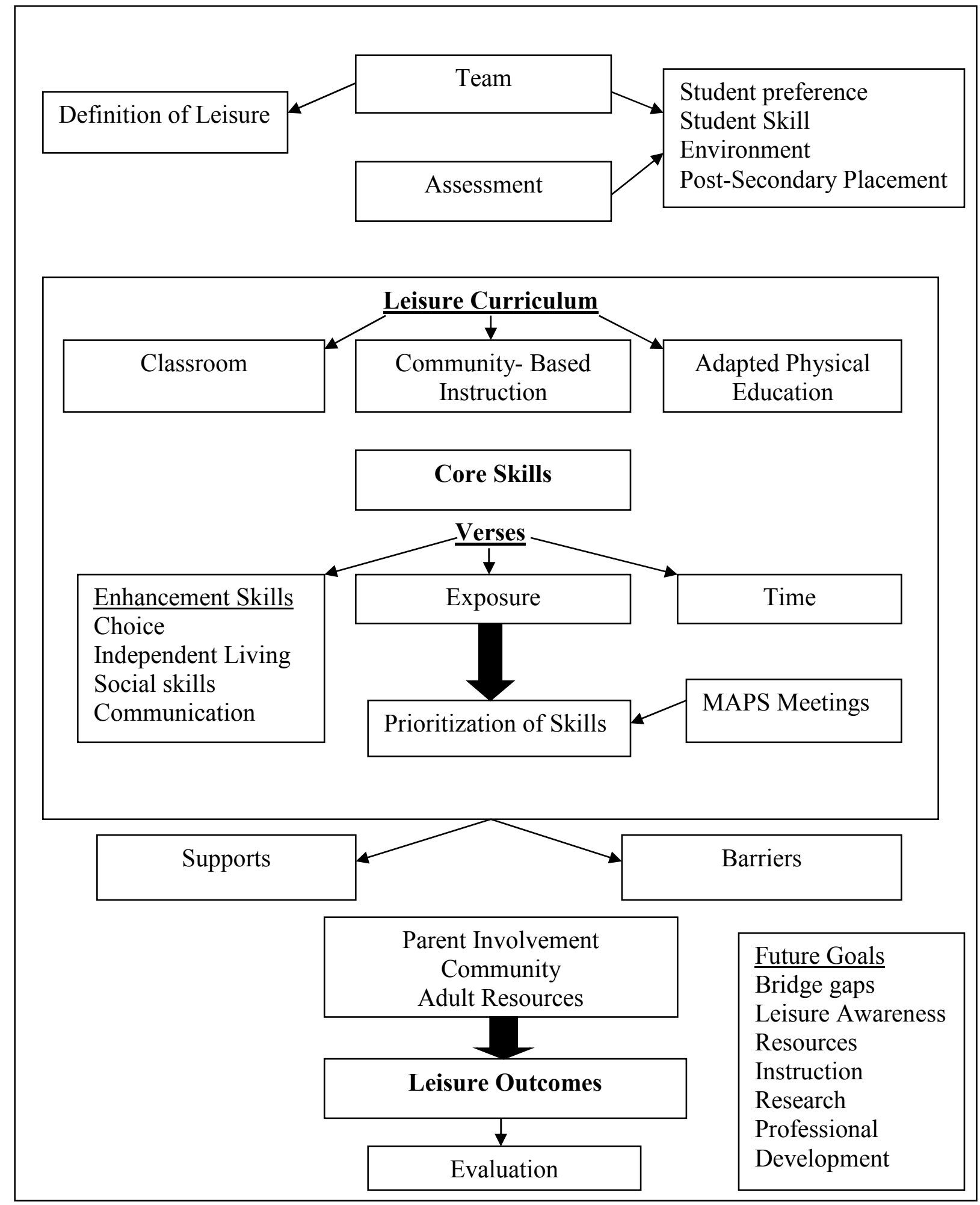

Figure 1. Flow chart based on participant's responses to curriculum in leisure education 
When I began this study, my values related to teaching students with severe disabilities included the importance of leisure education; however, I had an unclear picture of what leisure education was in schools. Through the interviewing process, I discovered themes, ideas, practices, and values that other teachers with positions like mine placed on leisure education. These interviews assisted me in further defining my understanding of and priorities related to addressing leisure outcomes in transition for students with severe disabilities. Based on my interpretation of the interview data, I created a visual map of leisure curriculum development. The next section is a guide through the visual map with an explanation of how teacher interview data influenced the map.

The first idea in creating the visual map was the formation of a team. Most educational processes involving making decisions for students with IEPs include a team approach. When discussing their practice related to leisure, many of the teachers in this study included family participation either in filling out surveys, taking students to adult service providers, or expressing concern about their future outcomes. For example, Emily stated, "in the beginning of the semester or the beginning of the year, I always give like a welcome to school kind of packet so that they and their parent would fill out. So, what kinds of sports, or what kinds of things does your child like? And that was really great for me because that kind of drove what my area of focus was for each month." Kim identified team members such as adaptive physical education teachers, other teachers, speech therapists, community members, and administrators. These team members were related to different parts of the educational process. Administration is needed to develop many programs and support the needs for transportation, staff, and schedules necessary to provide leisure curriculum outcomes. Speech therapists are important members of the team as many respondents expressed the need for communication as one of the enhancement skills for 
leisure participation. Many of the respondents who worked with adaptive physical education teachers relied on their expertise in teaching some of the recreation and leisure skills needed for leisure education. A team of people can bring different expertise to the formation of something that has not been done much before in an individualized leisure curriculum.

My visual representation then includes the need for assessment across different areas for leisure education. Assessment by different team members was also a common theme by participants. They conducted different types of assessments, but also relied on family for information based on their child's abilities and preferences. Without any concrete assessment made specifically for leisure education, different approaches to collecting information were used by different teachers. However, they identified similar areas that need assessment: student preference, student skill, assessment of available community activities and supports, and postsecondary placement. From these assessments, the participants would try to continue to develop activities that would address students' interests.

The visual representation then includes leisure curriculum, which is a more tangled web of ideas in the interview data, such as environments to teach these skills, types of skills that should be taught, and the prioritization of these skills. Participants had a wide range of responses about what leisure curriculum includes, reflecting their own personal value and definition of leisure education. Many of the participants tried to label current practices of classroom activities such as free time, social skill development, and building relationships as leisure curriculum. For example, the setting or location of leisure education was included in the classroom, in the community, or in adapted physical education class. Maggie stated about leisure outcomes, "we specifically related to recreation my students have in adapted PE. So, there is a lot of goals with that including like fitness goals, so students will choose an exercise machine of their choice and 
stay on it for 15 minutes." She then said that adapted PE, "is very organized and structured, absolutely, and our adaptive PE teacher is wonderful. She really makes sure that they are things that students can do in the community as well." All three areas gave opportunities to try different types of activities which led to the next idea of what are we teaching.

When discussing leisure education skills, participants focused on enhancement skills of choice, independence, social skills, and communication. When asked what skills should be taught in leisure education, Casey stated, "money management, communication skills, selfawareness, self-monitoring, and transition skill." These enhancement skills often related back to their value of developing friendships as a result of leisure activities or leisure skills. Other areas considered to be leisure included exposure and free time. Many teachers found that exposure and experience to activities helped them decide what they liked to do. Krissy stated, "I think if they haven't been exposed to certain things, I don't know if they, they might just think that they don't like it, but if they haven't had the opportunity to actually you know do that then..." They felt many of the students needed this exposure due to the barriers that they had when accessing different activities. Free time was often discussed as a form of leisure instruction. Many teachers talked about having free time for students to do activities they liked and to choose how to fill their free time.

In response to questions about structured leisure curriculum, many participants did not discuss approaches to developing core skills. However, a few participants said they taught classroom games, moving pieces during board games, and taking data on throwing skills. Maggie discussed the use of research to teach a student how to swim. Her approach to using constant time delay while in the pool made a different in teaching that skill for her student. Most 
of the teachers either did not use research to inform leisure curriculum or did not know of any research related to this area of education.

Prioritizing skills is the next important step in creating a longitudinal curriculum. Maggie had a system in place of using a MAPS meeting with input from a team of people. She then took the information and prioritized it in a grid system to decide the skills to teach the students. Other teachers had priorities that were based on their own observations on behavior, hygiene, and independent living skills. Others followed what their school felt was important, such as communication. Kim felt those social skills was her priority, because it was a skill that would be used the most.

The visual representation then includes supports and barriers as to leisure education and outcomes. From the discussion in all the areas of team, assessment, and leisure curriculum development, common responses included the supports they received and the barriers that made progress more difficult. The areas of parent involvement, community (people, resources, available leisure opportunities, transportation), and adult resources became both supports and barriers when making progress depending on a lot of individual factors. Kim stated in regards to family participation, “I don't know, I just feel like a big part of it rests on the family, like what they do and what you know what I mean, they are willing to pursuit, you know cause as a teacher we don't get enough time." With this information, the need to build on the natural supports, and overcome the individual barriers became and apparent factor in creating a healthy leisure curriculum.

The visual map includes leisure outcomes as the overall goal of leisure education. This question was positioned at the beginning of the interviews. However, leisure outcomes became the end to the map to an important visual of our overall goals. The outcomes discussion included 
a wide range of answers but primarily describing context rather than individual's actual leisure outcomes, revolving mostly around community agencies, parent participation, and the living placements. We also discussed future goals, including bridging gaps between schools, parents, agencies, and community opportunities; awareness of leisure education as a real area of education; resources for curriculum; support in creating a longitudinal curriculum; and continued research to support the importance in this area of education.

Finally, the visual representation shows the evaluation of leisure education. From the interviews, not much evaluation is occurring. However, reflecting and continual development of leisure education is needed in the beginning stages of creating best practices for teaching leisure education. 


\section{CHAPTER V: DISCUSSION}

\section{Findings}

This study was conducted to see how teachers were incorporating leisure outcomes and curriculum into transition planning for students with intellectual disabilities. The responses to the interview questions indicated that teachers found leisure outcomes to be important. However, creating a definition, assessment, and leisure curriculum were difficult for these teachers to implement in their classroom. Overall, the data did support the use of leisure education in the classroom. However, with the lack of research, many questions remain on the best practice in developing curriculum to address this topic.

\section{Teacher Viewpoints}

The interviews highlighted the different viewpoints and values teacher placed on leisure education. Their own personal values of what they believed about leisure education and the level of importance of leisure education reflected their current practices. These thoughts were in line with much of the quality of life discussion. Their viewpoints of friendship, health, stress, and behavior aligned with several of Schalock's eight domains such as interpersonal relationships, social inclusion, and physical well-being. These elements were the basis of quality of life, which the participants had hoped to extend to their students through leisure education (Schalock et al., 2016). The participants hoped that leisure would extend to meaningful relationships as they frequently discussed developing friendships as a leisure initiative. Maggie felt that, "leisure activities help generalize overall communication skill, but in a less formal way. And so, kids can shine in things that interest them and hopefully when they are with their peers or their friends in a shared leisure experience those people also have interests in it. And I think there is a lot of communication and bonding when you get people together that are liked minded, so there's a lot 
of inclusive opportunities through leisure." Claes et al. (2012) also found that meaningful relationships for students with severe disabilities formed through similar interest and leisure activities.

The participants' value of friendships developed via leisure education did not align with the original values reflected in the development of physical/leisure education in general education. The origin of physical activity was to establish pleasure, discipline, mental health, and physical fitness (McClean et al., 2008). Friendships were not discussed or included in the research on developing leisure and recreation programs. Other types of social activities were considered as more of an outside role of the school. From these differences, we can conclude that for special education students, the expectation of enhancement skills such as building relationships, communication, and social skills are different than for general education peers.

\section{Family Support}

The participants also discussed family influences on leisure education. Kim discussed family participation as a barrier. She stated, "some of the barriers was family participation like how willing are you to make this happen or to expose them to these activities. Sara describes limited involvement by parents. She stated, "my parents do take their kids around town. It's like little local trips here and there to the grocery stores, to the swimming pool which is great, but they don't get an opportunity to see really what's out there outside of our town." Molly discussed both types of parents. She said," I think it depends on where the student is going to end up. I think if they are in a house again where they are used to going and doing things outside of their home that will probably continue, but if it is possibly a student that maybe moving into a group home then if that student is the one that never got out of the house, then I think things get a little bit better as far as leisure outcomes for them.” Kleinert et al. (2007) did find that students 
with disabilities were included in a wide range of school and community activities, but were supported in these activities most by their family.

\section{Post-Secondary Placement}

Post-secondary placement was another topic of importance when discussing leisure education. The participants discussed the different opportunities available in the community and in the post-secondary setting. They felt that factors such as family values, community resources, and adult services greatly impacted the type of leisure activities that were available. They found importance in teaching skills that can be used in the community that they lived and leisured. These ideas also aligned with past research by Verdugo et al. (2012) when they describe the micro, meso, and macro systems of society. They explained how leisure education was important at all levels when considering the types of leisure. Leisure education is relevant in all three levels, as society must acknowledge the need for including people with disabilities at the macro level, community and agencies must adapt to meet the needs of people with disabilities at the meso level, and finally the individual must have the skills to access leisure activities at the micro level. With these thoughts, the participants should continue to assess the supports, the environments, and the individuals to build leisure education skills that follow these systems. Maggie talked about how her adapted PE program did a good job teaching skills that matched activities that occur in the community. Harner and Heel (1997) found similar importance in skill development in the areas and activities found in their environment.

The participants' responses also reached similar findings to Schalock's discussion of moderator and mediator in relationship to quality of life. These teachers took into consideration more environmental factors including personal demographic, organization, culture, family-unit factors, personal status, provider system, and community factors which can vary over time, age, 
and choices to quality of life. The participants valued a lot of personal preferences which allows choice and interests, but they did not discuss how leisure is fluid over age, interest, and environmental factors. Further discussion should occur on how leisure has the potential to change over time.

\section{Leisure Curriculum}

Discussing leisure curriculum seemed to be most challenging for the participants. Their current practices did include many important attributes of a curriculum such as choice making, social skills, independent living skills, peer group support, exposure to new activities, behavior, hygiene, and communication. Some of the skills discussed by the participants were also found important in research by Datillo. Datillo (2012) analyzed the type of content that should be in leisure education. These areas included awareness of self in leisure, appreciation of leisure, selfdetermination in leisure, decision-making skills, knowledge and utilization of resources, social interaction skills, and recreation activity skills. Badia et al. (2012) also found that choice and preference made a large difference when considering the quality of an activity. Exposure to new activities was also supported by research conducted by Modell and Valdez (2002). They found that people with intellectual disabilities should have the opportunity to choose to participate in community activities based on a variety of experiences and skills developed during their school years.

However, many other best practices in teaching students with severe disabilities were missing from the interview data. Shelden \& Hutchins (2008) identified the importance of using an ecological approach to curricular development which many of our participants did do. They looked for meaningful participation combined with family support. However, most of the participants did not individualize the curriculum to create a person-centered plan. Emily was 
one of the few to discuss doing a pre-school assessment that parents filled out and individually taught leisure skills each month related to the interests. Maggie was the only person who directly talked about person centered-planning through MAPS meetings. These meetings directed her in prioritizing skills based on person-centered planning. The approach of person centered-planning was also linked to quality of life by Verdugo et. al (2005) when discussing valued outcomes.

The best practices highlighted by Shelden and Hutchins (2008) of teaching whole task, constant time delay, chaining, systematic fading of prompts and reinforces, and explicit instruction of social skill to be effective approaches when teaching students with severe disabilities were seldom used. Teaching leisure curriculum was vaguely discussed by Maggie and Emily. Maggie talked specifically about researching the most appropriate approach to teaching swimming, and chose to teach it with systematic instruction. Maggie chose to use the system of most to least prompts when teaching specific skills. However, most of the interviews lacked any discussion on direct instruction or systematic instruction of skills to people with disabilities. More often, participants talked about the lack of research associated with leisure education.

\section{Barriers}

Both the literature and the interviews highlighted common barriers in implementing leisure recreation. However, the participants were more specific to categories related to education. These categories included resources, time, transportation, behavior, awareness, and adult services. The participants discussed these barriers along with future goals for leisure programs. As seen in the visual, bridging gaps between schools, peers, adult services providers, 
families, and resources were high on the priority list. The current disconnects have a negative effect on leisure outcomes and quality of life.

The research showed barriers to be linked lack of resources and to low income to perception of barriers. Datillo (2012) found that a lack of reliable transportation was related to low income for many people with disabilities. Without basic resources, leisure was not a priority for many of the individuals, families, and outside sources (Datillo, 2012). Badia et al. (2012) found that the perception of barriers significantly accounted for the different levels of participation in activities at home and in social activities. They found that reduced participation was due to not having enough time, being tired, being too old, the need to depend on another person to carry out the activity, and the fear of being mocked. Further research on barriers should focus on school related barriers to leisure education.

\section{Conclusions}

The participants did not have a lot of knowledge and resources attached to leisure education. Awareness on leisure education is important to establish to ensure that leisure education has a place during the school day. The lack of knowledge, research, and resources has prevented growth in leisure education while vocational education has continued to be a prominent focus. Through awareness and research, structure, programs, and practices for leisure education can become a part of current classroom curriculum. Awareness of leisure education is the first step in making changes towards building a leisure curriculum.

All participants' viewpoints and values portrayed similar themes as the components of quality of life discussed by Schalock. All participants wanted their students to fill their postsecondary time with friendships and meaningful activities. The participants heavily focused on the need to develop future friendships to have a successful leisure outcome. However, the idea 
of teaching social development to ensure friendships leaves out the importance of teaching core skills to ensure that the individual can successfully participate or partially participate in the activity. This is important especially for those students who may not value friendships and relationships as much as specific activities. The development of these separate skills allows for a differentiation and allows for more consideration of preferences to prevent possible negative leisure outcomes. The negative leisure outcomes of isolation, sedentary lifestyle, and reliance on electronics as sole entertainment was concerning to both participants and parents of these students with disabilities. These negative outcomes along with the ideas of quality of life related to leisure education is why the discussion of leisure education has become important for further investigation.

By having the end goal of improving leisure outcomes, assessment is also useful in improving leisure outcomes. The participants used a wide variety of assessments to gather information including interest inventories, preference assessments, exit tickets, and informal observations. Researches also used preference assessments to decide what to teach. Helps and Herzberg (2013), Wall et al. (1999), Cannella-Malone et al. (2016), and Wall and Gast (1997) used preferred activities, preference assessments or interest inventories to decide what leisure skill to teach. Yilmaz et al. (2010) and Carlile, et al. (2013) used peer preference in selecting leisure skills to teach students using systematic instruction. Finally, Pence and Dymond (2015), Vandercook (1991), and Zisimopoulos et al. (2011) chose their skills in accordance to inclusion and environments that the skills were to be used. These practices are all valuable, but there is also a need for assessments to address specific core skill development. Without these assessments, student growth, feedback on knowledge of skill, and longitudinal skill development is much more difficult to measure. 
Finally, the need for a structured approach to developing a longitudinal leisure curriculum is necessary to achieve meaningful leisure outcomes. Past curriculums have highlighted different types of leisure education programs. For example, Wake Leisure Education Program (1990) comprised of 10 units on varying topics addressing leisure related needs of students with severe disabilities in transition. The curriculum's ten units included: a) leisure awareness, b) self-awareness in leisure, c) leisure opportunities, d) community resource awareness, e) barriers, f) personal resources and responsibility, g) planning, h) planning an outing, i) the outing, and j) outing evaluation (Bedini et al., 1993). This resource is valuable and worth investigating, but updates are needed as materials becomes outdated especially with the changes in technology. As leisure transforms based on trends in society and best practices in education, materials should continue to be updated. However, the educational focus has not been on leisure education making much of past curriculum outdated, and obsolete as seen in the example. Consideration for leisure core skills, enhancement skills, and community characteristics should also have input into the development of leisure curriculum.

\section{Limitations}

Limitation should be considered when examining the results of this study. The idea of leisure is not a common topic of conversation currently in education. As interviews occurred, participants would start out with one idea of leisure education, but then make contradicting statements sometimes in the same sentence while at other times by the end of the interview. I contribute these contradictions due to the unfamiliarity of the topic along with my inexperience in interviewing participants. These contradictions should be noted in future research to either address these contradictions or to work to avoid though better questioning or preparation. 
As an exploratory study, participants were selected both at the secondary and middle school ages. Those participants at the middle school did not have the experience of working with an IEP plan for post-secondary purposes. Their inputs differed than a high school teacher based on the familiarity high school teachers have with IEP plans and adult services.

Another limitation included the sample size of interviewed participants. The sample of participants were located within a 60 -mile radius of my hometown. This population size represented a small area of the Midwest which limited other practices outside of this area. This limitation prevents the research to include other states with different approaches to transition planning.

Finally, my lack of interviewing experience limited the type of information gathered through the question and follow up question sequence. Though guided by a chair and thesis committee, further questioning would have collected additional meaningful data. However, member checks did assist in clearing up confusing and verifying information gathered from the interviews.

\section{Implications for Future Research}

This study examined the current beliefs and practices of leisure education in relationship to students with severe disabilities. The participants reflected on their own definitions of leisure, current leisure outcomes, and the types of assessment and curriculum developed to promote leisure education. A replication of this study or a similar study would allow for more participants with different backgrounds, environments, and practices related to leisure education.

Future research should include a more in-depth exploration of best practice in developing leisure curriculum. For leisure education, Modell and Valdez (2002) suggested carefully planning for and developing a wide range of community sport, recreation, and leisure activities 
to enhance the depth of participation. This exploration should include looking at the location skills are taught, goals written related to core skills versus enhancement skills, development of meaningful leisure assessments, current leisure outcomes for post-secondary students, and most efficient way to deliver curriculum. These areas of discovery would continue to develop a structured approach in developing leisure education.

This study created additional questions that need to be addressed in future studies to continue to understand the challenges of leisure outcomes. First, how should we assess leisure education core skill? What skills should be taught in a leisure education curriculum? How do we prioritize teaching core skills and enhancement skills? Finally, how do we evaluate leisure outcomes in a post-secondary setting? These questions will continue the discussion on creating a base of ideas to continue to develop a curriculum for leisure education.

All the participants struggled to describe a cohesive leisure educational process. The participants reported on a variety of assessments and general enhancement skills that would benefit leisure education, but did not describe how to teach core leisure skills and evaluate outcomes. Future research would benefit finding a balance of teaching enhancement skills, but also teach the core skill as well. Finally, evaluating leisure outcomes can inform teachers on the current post-secondary experiences leading to a more effective curriculum.

\section{Implications for Future Practice}

Leisure education has a place in the educational system. Future practices should include the development of awareness through college prep programs, professional development opportunities, or collaborative efforts through outside services. From the developed awareness of leisure education, professionals should start the discussion on how to create a cohesive 
program. The basis would be to develop a universal definition that can be used by professionals as a starting point for future development.

Next, leisure education should be more included in the IEP process when it comes to transitioning into the post-secondary settings. Establishing a place in the IEP will encourage teachers to use assessments, teach goals related to leisure education, and work on bridging the gaps to outside adult service providers. Understanding leisure outcomes in a post-secondary setting can also be beneficial when evaluating the effectiveness of an IEP plan.

Leisure curriculum development should also be a priority for future practices. Limited research and curriculum structure has impeded this area of education. By developing a program including both core skills, and enhancement skills could provide structure and research-based practices that are much needed in this area of education. These types of resources will also help teacher develop a curriculum that can relate to the needs of the students and their own personal beliefs and values.

Professional development and training should also be developed in the process of implementing a meaningful curriculum. Systematic instruction and leisure education skills should be researched and developed to establish best practices in teaching leisure education skills. Systematic instruction should be referenced and taught specifically to leisure education in both teacher prep programs and in school improvement days. Data collection should also be taught to show student growth.

Finally, leisure skills should be meaningful to the individual, family, and environment in which they will live. Leisure education should be connected to both community and home activities. They should be fluid as individuals change in interest and in age. By establishing a systematic way to assess leisure enjoyment, these activities can change as the individual change. 


\section{REFERENCES}

Aitchison, C. (2009). Exclusive discourses: leisure studies and disability. Leisure Studies, 28, 375-386. doi.org/10.1080/02614360903125096

Badia, M., Orgaz, B. M., Verdugo, M. A., Ullan, A. M., \& Martinez, M. M. (2013).

Relationships between leisure participation and quality of life of people with developmental disabilities. Journal of Applied Research in Intellectual Disabilities. 26, 533-545. doi:10.1111/jar.12052

Badia, M., Orgaz, B. M., Verdugo, M. A., Ullán, A. M., \& Martínez, M. M. (2011). Personal factors and perceived barriers to participation in leisure activities for young and adults with developmental disabilities. Research in Developmental Disabilities, 32, 2055-2063. doi:10.1016/j.ridd.2011.08.007

Bedini, L. A., Bullock, C. C., \& Driscoll, L. B. (1993). The effects of leisure education on factors contributing to the successful transition of students with mental retardation from school to adult life. Therapeutic Recreation Journal, 27, 70-82.

Blum-Dimaya, A., Reeve, S. A., Reeve, K. F., \& Hoch, H. (2010). Teaching children with autism to play a video game using activity schedules and game-embedded simultaneous video modeling. Education and Treatment of Children, 1, 351.

Brajša-Žganec, A., Merkaš, M., \& Šverko, I. (2011). Quality of life and leisure activities: How do leisure activities contribute to subjective well-being?. Social Indicators Research. 102. 81-91.

Brown, I., \& Brown, R. I. (2009). Choice as an aspect of quality of life for people with intellectual disabilities. Journal of Policy and Practice in Intellectual Disabilities. 6. 11-18. doi.10.1111/j.1741-1130.2008.00198.x 
Brown, S. L., Nobiling, D. B., Teufel, J., \& Birch, D. A. (2011). Are kids too busy? Early adolescents' perceptions of discretionary activities, overscheduling, and stress. Journal of School Health, 81, 574-580. doi.org/10.1111/j.1746-1561.2011.00629.x

Cannella-Malone, H. I., Miller, O., Schaefer, J. M., Jimenez, E. D., Page, E. J., \& Sabielny, L. M. (2016). Using video prompting to teach leisure skills to students with significant disabilities. Exceptional Children, 82, 463-478. doi.org/10.1177/0014402915598778

Cannella-Malone, H. I., Mizrachi, S. V., Sabielny, L. M., \& Jimenez, E. D. (2013). Teaching physical activities to students with significant disabilities using video modeling. Developmental Neurorehabilitation, 16, 145-154. doi:10.3109/17518423.2012.763192

Carlile, K. A., Reeve, S. A., Reeve, K. F., \& DeBar, R. M. (2013). Using activity schedules on the iPod touch to teach leisure skills to children with autism. Education and Treatment of Children, 1, 33 .

Claes, C., Van Hove, G., Vandevelde, S., van Loon, J., \& Schalock, R. (2012). The influence of supports strategies, environmental factors, and client characteristics on quality of life-related personal outcomes. Research in Developmental Disabilities, 33, 96-103. doi:10.1016/j.ridd.2011.08.024

Cowden, J. E., Wright, J., \& Gant, S. A. (1984). Gary W., et al. v. the State of Louisiana implications for adapted physical education, recreation, and leisure education. Adapted Physical Activity Quarterly, 1, 97.

Dattilo, J. (2013). Inclusive leisure and individuals with intellectual disability. Inclusion, 1, 7688. DOI: $10.1352 / 2326-6988-1.1 .076$

Dattilo, J. (2008). Leisure education program planning: A systematic approach. State College, PA: Venture Publishing. 
Dattilo, J. (2012). Inclusive leisure services. State College, PA: Venture Publishing

Dollar, C. A., Fredrick, L. D., Alberto, P. A., \& Luke, J. K. (2012). Using simultaneous prompting to teach independent living and leisure skills to adults with severe intellectual disabilities. Research in Developmental Disabilities, 33. 189-195.

doi:10.1016/j.ridd.2011.09.001

Gies, M., \& Porretta, D. (2015). Video prompting and its application to physical activity settings for individuals with developmental disabilities. Palaestra, 29, 31-35.

Harner, C. J., \& Heal, L. W. (1993). The multifaceted lifestyle satisfaction scale (MLSS): Psychometric properties of an interview schedule for assessing personal satisfaction of adults with limited intelligence. Research in Developmental Disabilities, 14, 221-236. doi:10.1016/0891-4222(93)90032-F

Helps, D. H., \& Herzberg, T. S. (2013). The use of an iPad2 as a leisure activity for a student with multiple disabilities. Journal of Visual Impairment and Blindness, 107, 232-236.

Hogg, J., \& Cavet, J. (1995). Making leisure provision for people with profound learning and multiple disabilities. London; New York: Chapman \& Hall.

Hutchison, P., \& McGill, J. (1992). Leisure, integration, and community. Concord, Ontario: Leisurability Publications, 1992.

Joswiak, K. F. (1989). Leisure education: Program materials for persons with developmental disabilities. State College, PA: Venture Publishing.

Kleinert, H. L., Miracle, S., \& Sheppard-Jones, K. (2007). Including students with moderate and severe intellectual disabilities in school extracurricular and community recreation activities. Intellectual and Developmental Disabilities. 45, 46-55. doi: 10.1352/19349556(2007)45[46:ISWMAS]2.0.CO;2 
Krueger, R. A., \& Casey, M. A. (2000). Focus groups: A practical guide for applied research. Thousand Oaks, California: Sage Publications.

Krueger, D. L., DiRocco, P., \& Felix, M. (2000). Obstacles adapted physical education specialists encounter when developing transition plans. Adapted Physical Activity Quarterly, 17, 222. doi.org/10.1123/apaq.17.2.222

Leisure education in the schools. (2012). Journal of Physical Education, Recreation \& Dance, 83, 50-51. doi:10.1080/07303084.2012.10598712

McDonnell, J. J., Hardman, M. L., \& McDonnell, A. P. (2003). An introduction to persons with moderate and severe disabilities: Educational and social issues. Boston: Allyn \& Bacon.

McLean, D. D., Hurd, A. R., \& Rogers, N. B. (2008). Kraus' recreation and leisure in modern society. Sudbury, Mass.: Jones and Bartlett Publishers.

Mithaug, D. E., Horiuchi, C. N., \& Fanning, P. N. (1985). A report on the Colorado statewide follow-up survey of special education students. Exceptional Children, 51, 397-404. doi.org/10.1177/001440298505100505

Modell, S. J., \& Valdez, L. A. (2002). Beyond bowling: Transition planning for students with disabilities. TEACHING Exceptional Children, 34, 46-52.

Nota, L., Ferrari, L., Soresi, S., \& Wehmeyer, M. (2007). Self-determination, social abilities and the quality of life of people with intellectual disability. Journal of Intellectual Disability Research, 51, 850-865. Doi:10.1111/j.1365-2788.2006.00939.x

Patterson, I., \& Pegg, S. (2009). Serious leisure and people with intellectual disabilities: Benefits and opportunities. Leisure Studies, 28, 387-402. doi:10.1080/02614360903071688 
Pence, A. R., \& Dymond, S. K. (2016). Teachers' beliefs about the participation of students with severe disabilities in school clubs. Research and Practice for Persons with Severe Disabilities, 41, 52-68. doi:10.1177/1540796915626009

Reardon, R., \& Mundy, J. (1984). Career education and leisure education: Toward a K-12 life/development synthesis. Journal of Career Development. 11, 110-118.

Reinders, H. S., \& Schalock, R. L. (2014). How organizations can enhance the quality of life of their clients and assess their results: The concept of QOL enhancement. AJIDD-American Journal on Intellectual and Developmental Disabilities. 119. 291-302. doi.org/10.1352/1944-7558-119.4.291

Ryndak, D. L., \& Alper, S. (2003). Curriculum and instruction for students with significant disabilities in inclusive settings. (2nd ed.). Boston: Allyn and Bacon.

Schalock, R. R., \& A1.], .. [. (2010). Intellectual disability definition, classification and systems of supports. Washington: American Association on Intellectual and Developmental Disabilities.

Schalock, R. L., Verdugo, M. A., Gomez, L. E., \& Reinders, H. S. (2016). Moving us toward a theory of individual quality of life. American Journal on Intellectual and Developmental Disabilities, 121, 1-12. doi:10.1352/1944-7558-121.1.1

Schalock, R. L., Verdugo, M. A., Jenaro, C., Wang, M., Wehmeyer, M., Jiancheng, X., \& Lachapelle, Y. (2005). Cross-cultural study of quality of life indicators. American Journal on Mental Retardation, 110, 298-311. doi:10.1352/08958017(2005)110[298:CSOQOL]2.0.CO;2

Schleien, S. J., Meyer, L., Heyne, L., \& Biel-Brandt, B. (1995). Lifelong leisure skills and lifestyles for persons with developmental disabilities. Baltimore: Paul H. Brookes. 
Sheldon, D. L., \& Hutchins, M. P., (2008). Personalized curriculum development. In H. P. Parette, \& G.R. Peterson-Karlan $\left(2^{\text {nd }}\right)$, Research-based practices in developmental disabilities, (235-252). Austin, Texas. Pro-Ed.

Simpkins, S. D., Vest, A. E. \& Becnel, J. N. (2010), Participating in sport and music activities in adolescence: The role of activity participation and motivational beliefs during elementary school. Journal Youth Adolescence 39: 1368. doi.org/10.1007/s10964-009-9448-2

Snell, M. E. (2009). Advances in instruction. In S. L. Odom, R. H. Horner, M. E. Snell, \& J. Blacher, Handbook of developmental disabilities. (249-268). New York: The Guilford Press.

Vandercook, T. (1991). Leisure instruction outcomes: Criterion performance, positive interactions, and acceptance. Journal of Special Education, 25, 320. doi.org/10.1177/002246699102500305

Verdugo, M. A., Navas, P., Gómez, L. E., \& Schalock, R. L. (2012). The concept of quality of life and its role in enhancing human rights in the field of intellectual disability. Journal of Intellectual Disability Research, 56, 1036-1045. doi:10.1111/j.1365-2788.2012.01585.x

Verdugo, M. A., Schalock, R. L., Keith, K. D., \& Stancliffe, R. J. (2005). Quality of life and its measurement: Important principles and guidelines. Journal of Intellectual Disability Research, 49, 707-717. doi: 10.1111/j.1365-2788.2005.00739.x

Wall, M. E., \& Gast, D. L. (1997). Caregivers' use of constant time delay to teach leisure skills to adolescents or young adults with moderate or severe intellectual disabilities. Education and Training in Mental Retardation and Developmental Disabilities, 1, 340. 
Wall, M., Gast, D., \& Royston, P. (1999). Leisure skills instruction for adolescents with severe or profound developmental disabilities. Journal of Developmental \& Physical Disabilities, 11, 193. doi:10.1023/A:1021803331413

Wallhead, T. L., Garn, A. C., \& Vidoni, C. (2014). Effect of a sport education program on motivation for physical education and leisure-time physical activity. Research Quarterly for Exercise \& Sport, 85, 478-487. doi.org/10.1080/02701367.2014.961051

Washington, B. H., Hughes, C., \& Copeland, S.R. (2014). Quality of life. In K. J. Storey, \& D. Hunter, (3rd Ed). The road ahead: transition to adult life for persons with disabilities. (pp. 255-269). Amsterdam: IOS Press.

Wilcox, B., \& Bellamy, G. T. (1987). A comprehensive guide to the activities catalog: an alternative curriculum for youth and adults with severe disabilities. Baltimore: P.H. Brookes.

Yilmaz, I., Konukman, F., Birkan, B., Ozen, A., Yanardag, M., \& Camursoy, I. (2010). Effects of constant time delay procedure on the halliwick's method of swimming rotation skills for children with autism. Education and Training in Developmental Disabilities, 45, 124-135.

Zisimopoulos, D., Sigafoos, J., \& Koutromanos, G. (2011). Using video prompting and constant time delay to teach an internet search basic skill to students with intellectual disabilities. Education and Training in Autism and Developmental Disabilities, 1, 238. 


\section{APPENDIX A: INTERVIEW QUESTIONS}

1. Let's start by talking about leisure outcomes. What comes to mind for you when we use that term?

2. Describe leisure outcomes for your students?

3. How does it relate to post-secondary setting?

4. What does it mean to address leisure in schools?

5. Describe your current practices in leisure education.

a. Outcomes curriculum instruction

b. How has leisure been included in the transition process? How could leisure education be included in individualized education plans?

c. In what other ways would you like to address leisure outcomes in your curricula?

d. What barriers have you experienced in considering leisure?

6. What future goals do you have for leisure education? What changes do you see necessary to target this area of transition?

7. What if any value do you place in leisure education?

8. What else should we discuss related to leisure education for our students? 